\title{
1 A barley gene cluster for the biosynthesis of diterpenoid 2 phytoalexins
}

3

4 Yaming Liu', Gerd U. Balcke ${ }^{1}$, Andrea Porzel ${ }^{2}$, Lisa Mahdi ${ }^{3}$, Anja Scherr-Henning ${ }^{1}$, Ulschan

5 Bathe $^{1}$, Alga Zuccaro ${ }^{3}$ and Alain Tissier $^{1 *}$

6

$7{ }^{1}$ Department of Cell and Metabolic Biology, Leibniz Institute of Plant Biochemistry, Weinberg

8 3, 06120 Halle (Saale), Germany

$9{ }^{2}$ Department of Bioorganic Chemistry, Leibniz Institute of Plant Biochemistry, Weinberg 3, 1006120 Halle (Saale), Germany

$11{ }^{3}$ Institute for Plant Sciences, Cluster of Excellence on Plant Sciences (CEPLAS), Cologne

12 Biocenter, University of Cologne, Zülpicher Straße 47a, 50674 Cologne, Germany

14 *Author for correspondence: Alain Tissier, alain.tissier@ipb-halle.de

16 ORCID IDs:

17 Yaming Liu: 0000-0002-8832-8398

18 Gerd Balcke: 0000-0002-0475-0672

19 Andrea Porzel: 0000-0002-8148-6895

20 Lisa Mahdi: 0000-0003-1559-5492

21 Ulschan Bathe : 0000-0002-0454-502X

22 Alga Zuccaro: 0000-0002-8026-0114

23 Alain Tissier: 0000-0002-9406-4245 


\section{Barley diterpenoid gene cluster}

\section{Abstract}

25 Phytoalexins are specialized metabolites that are induced upon pathogen infection and 26 contribute to the defense arsenal of plants. Maize and rice produce multiple diterpenoid 27 phytoalexins and there is evidence from genomic sequences that other monocots may also produce diterpenoid phytoalexins. Here we report on the identification and characterization of a gene cluster in barley (Hordeum vulgare cv. Golden Promise) that is involved in the production of a set of labdane-related diterpenoids upon infection of roots by the fungal pathogen Bipolaris sorokiniana. The cluster is localized on chromosome 2, covers over 600 $\mathrm{kb}$ and comprises genes coding for a (+)-copalyl diphosphate synthase (HvCPS2), a kaurene synthase like (HvKSL4) and several cytochrome P450 oxygenases (CYPs). Expression of HvCPS2 and HvKSL4 in yeast and Nicotiana benthamiana resulted in the production of a single major product, whose structure was determined to be of the cleistanthane type and was named hordediene. Co-expression of HvCPS2, HvKSL4 and one of the CYPs from the cluster (CYP89E31) afforded two additional products, hordetriene and 11-hydroxyhordetriene. Both of these compounds could be detected in extracts of barley roots infected by $B$. sorokiniana, validating the function of these genes in planta. Furthermore, diterpenoids with multiple oxidations and with molecular masses of 316,318 and 332 were induced in infected barley roots and secreted in the medium, indicating that additional oxidases, possibly from the same genomic cluster are involved in the production of these phytoalexins.

43 Our results provide the basis for further investigation of the role of this gene cluster in the 44 defense of barley against pathogens and more generally in the interaction with the microbiome. 
Barley diterpenoid gene cluster

46

47

48

49

50

51

52

53

54

55

56

57

58

59

60

61

62

63

64

65

66

67

68

69

70

71

72

73

74

75

76

77

78

79

80

81

\section{Introduction}

Monocotyledons contribute some of the most important staple crops worldwide, including the three major ones maize (Zea mays), wheat (Triticum aestivum) and rice (Oryza sativa) that cover a large part of calorie intake by humans worldwide (Awika, 2011). Behind these three species, barley (Hordeum vulgare) is the fourth most important grain crop with an annual production of over 140 million tons and with an harvest area of almost 48 million ha worldwide in 2018 (Table S1). Barley is grown in temperate climates and primarily for animal feed, but also to provide substrate for the fermentation of beverages (e.g. beer), and for a range of health promoting products. It is one of the earliest cultivated crops with supporting archaeological evidence from the fertile crescent region dating to as far back as over 10,000 years before present (BP) (Badr et al., 2000). The initial use of barley was for food, but it was then later replaced by wheat (Riehl, 2019). Cultivated barley is one of 31 Hordeum species, with $H$. vulgare subsp. spontaneum believed to be the wild ancestor of cultivated barley (Badr et al., 2000). The close relatedness of barley to wheat and its diploid nature $(2 n=14)$ make it a relevant model species for the study of temperate cereal crops. A first draft of its genome was published in 2016 and was recently updated (Beier et al., 2017; Mascher et al., 2017; Monat et al., 2019). Furthermore, genetic transformation and gene editing in barley are now well established, providing a complete toolbox for functional genetics in this species (Hensel, 2020).

Plants synthesize a complex array of secondary metabolites that contribute to the response and adaptation to a range of biotic or abiotic stresses. These metabolites can be produced constitutively, in a tissue specific manner or upon challenge by specific stresses, be they biotic or abiotic. Whereas some metabolites are common to a wide range of species, others are restricted to a species or to a taxon, thereby determining a species or taxon metabolite signature, a feature that led to the denomination "specialized metabolites" (Pichersky et al., 2006; Pichersky and Lewinsohn, 2011).

Plant pathogenic fungi impose a major burden on crop yield, and this impact is expected to increase with climate change (Miedaner and Juroszek, 2021). As the use of agrochemicals is increasingly under scrutiny by environmental agencies and while single gene-for-gene resistance may be rapidly overcome in a changing climate, there is a strong need for more durable resistance traits. The fungus Bipolaris sorokiniana (syn. Cochliobolus sativus) is the pathogenic agent of spot blotch and root rot in wheat and barley and is particularly prevalent in regions with a warmer climate (Rosyara et al., 2010) and therefore represents a typical future important threat in regions with a temperate climate in the context of global warming. B. sorokiniana can infect both aerial and underground parts of the plant but knowledge on how it interacts with roots is still rather limited (Sarkar et al., 2019). 
82 There is widespread evidence that infection of plants by microbial pathogens triggers the

83 production of a secondary metabolites (also called specialized metabolites) that exhibit 84 antimicrobial or antioxidant activities (Ahuja et al., 2012). These compounds, called phytoalexins, are not restricted to a particular chemical class, with examples among

86

87

88

89

90

91

92

93

94

95

96

97

98

99

100

101

102

103

104

105

106

107

108

109

110

111

112

113

114

115

116

117

118 phenylpropanoids, alkaloids or terpenoids (Ahuja et al., 2012). This is also the case in Monocotyledons, a plant clade that includes some of the most important food crops worldwide. In barley, there is a number of reports of various phytoalexins produced in response to diverse pathogens. These include phenylamides, such as the dimeric hordatine $A$ and $B$, the indole-derived gramine, benzoxazinones such as 2,4-dihydroxy-1,4-benzoxazin3-one (DIBOA), methoxychalcones as well as tyramine and related amines (Ishihara et al., 2017; Ube et al., 2017; Ube et al., 2021). However, in contrast to other monocotyledon crops such as maize and rice, no sesqui- or diterpenoid phytoalexins have been identified in barley yet. There is now extensive data available on the nature and biosynthesis of a range of terpenoid phytoalexins in these important crop species. Rice produces several classes of labdane-related diterpenoids, including momilactones (A and B) (Kato et al., 1973; Cartwright et al., 1977), phytocassanes, oryzalexins (Akatsuka et al., 1983; Kono et al., 1984; Sekido et al., 1986; Kato et al., 1993, 1994) and oryzalides (Watanabe et al., 1990; Kono et al., 1991) as well as the macrocyclic ent-oxodepressin (Inoue et al., 2013). Maize produces dolabralexins and kauralexins, both labdane-related diterpenoid phytoalexins (Schmelz et al., 2011), as well as zealexins, which are sesquiterpenoids (Huffaker et al., 2011).

Biosynthesis of terpenoids starts by the conversion of linear isoprenyl diphosphate chains by terpene synthases to either linear or cyclic terpenes or terpene alcohols. In the case of diterpenoids, the precursor is typically all-trans-geranylgeranyl diphosphate (here abbreviated as GGPP) (Bohlmann et al., 1998), although in some isolated cases it is the allcis-isomer, nerylneryl diphoshate (Zi et al., 2014). Diterpene synthases (diTPS) are classified according to the mechanism underlying the initiation of the cyclization reaction. Thus class I diTPS initiate the reaction by dephosphorylation whereas class II do it by protonation of the terminal isoprenic double bond (Peters, 2010). The main products of class II diTPS are entcopalyl diphosphate (ent-CPP), the precursor of the gibberellins, and the other stereoisomers syn-copalyl diphosphate (syn-CPP) and CPP of normal configuration (Peters, 2010). In addition, there are other products of class II diTPS with a slightly different core structure, such as clerodienyl or halimadienyl diphosphates, as well as products with an alcohol function (Nakano et al., 2005; Sallaud et al., 2012; Pelot et al., 2017). Because the products of class II diTPS still contain a diphosphate group, class I diTPS can convert them to olefinic diterpenes or diterpene alcohols. The sequential reactions catalysed by class II and class I diTPS lead to the broad group of labdane-related diterpenes, which have in common a core bicyclic decalin ring structure (Peters, 2010). Apart from ent-oxodepressin, which has a 
119 macrocyclic structure, all diterpenoid phytoalexins from monocots identified so far belong to 120 the labdane-related group. Following cyclization by diTPS, diterpene backbones are then 121 oxidized at different positions and in a stereospecific way. Cytochrome P450 oxygenases 122 (CYPs) are the most frequently involved in these oxidations (Bathe and Tissier, 2019), but 123 other classes of enzymes such as 2-oxoglutarate dependent dioxygenases in gibberellin 124 biosynthesis (Hedden and Kamiya, 1997) or short-chain dehydrogenases/reductases as in 125 momilactone biosynthesis (Kitaoka et al., 2016) can also play a role in functionalizing 126 diterpenes. These oxidations can sometimes lead to backbone rearrangements and, 127 importantly, provide anchoring points, such as hydroxyl or carboxyl groups, for further 128 modifications by conjugating enzymes (Long et al., 2008; Rontein et al., 2008). Thus, sugar, 129 acyl, or benzoyl groups can decorate the oxidized diterpene core and provide added 130 functionalities.

131 In recent years the elucidation of the biosynthesis of rice and maize diterpenoid phytoalexins 132 has progressed significantly (Murphy and Zerbe, 2020). In rice, the labdane-related 133 diterpenoids are derived from either ent- or syn-copalyl diphosphate, whereas the maize 134 diterpenoid phytolexins derive from ent-CPP. In addition to the diTPS, which produce the 135 diterpene backbones of these phytoalexins, a number of CYPs are involved in the 136 functionalization of these backbones. Notably, both in maize and rice, some of the genes for 137 the biosynthesis of terpenoid phytoalexins occur are physically associated in chromosomal 138 clusters (Shimura et al., 2007; Wang et al., 2011; Ding et al., 2020; Liang et al., 2021).

139 Here we present the identification and characterization of a diterpenoid phytoalexin 140 biosynthesis cluster in barley. We show that genes in this cluster are strongly induced in 141 roots by a barley fungal pathogen, $B$. sorokiniana and we characterize the first biosynthesis 142 steps, consisting of a copalyl diphosphate synthase, a kaurene synthase like and a CYP. 143 Notably, the diterpene backbone produced by the CPS/KSL enzymes belong to the 144 cleistanthane group of labdane-related diterpenoids. To the best of our knowledge, this 145 diterpene backbone has not been detected yet in grasses. We also detected diterpenoid 146 phytoalexins in barley roots and in high amounts in the root exudate as well as the 147 intermediates produced by the first three enzymes of the pathway.

\section{Results}

\section{Identification of a diterpenoid biosynthesis gene cluster in barley chromosome 2}

152 In previous work, we generated transcriptome data of barley roots infected with either a 153 fungal pathogen, Bipolaris sorokiniana, or a beneficial root endophyte, Serendipita vermifera, 154 or both in local or systemic context (Sarkar et al., 2019). We observed that a number of 155 genes from the MEP pathway as well as a number of genes from a region in chromosome 2 
156

157

158

159

160

161

162

163

164

165

166

167

168

169

170

171

172

173

174

175

176

177

178

179

180

181

182

183

184

185

186

187

188

189

190

191

192

encoding terpene synthases and cytochrome P450 oxygenases are strongly induced by the fungal pathogen B. sorokiniana and moderately by S. vermifera (Fig. 1). In the MorexV2 version of the barley genome (Monat et al., 2019), this cluster spans over $600 \mathrm{~kb}$ and contains one gene encoding a copalyl diphosphate synthase (CPS), one kaurene-synthase like (KSL), 8 CYP and one asparaginase (Fig. 1). The cluster also harbors a number of pseudogenes, including five CYPs and four CPS. As is frequently the case in regions of the genome with multiple duplications, the early versions of the genome sequence (including MorexV1 and MorexV2) still contain a number of gaps, and it is likely that the number of genes and pseudogenes in this cluster evolves as more accurate sequences become available.

\section{Phylogenetic analysis of the CPS and KSL genes in the chromosome 2 cluster}

To better characterize the genes of the cluster, we performed a phylogenetic analysis. Earlier publications reported on the identification and biochemical characterization of HvCPS1 as an ent-CDP synthase (Spielmeyer et al., 2004; Wu et al., 2012). The strong similarity of HvCPS1 to TaCPS3 and TaCPS4, both of which are ent-CDP synthases, and the exclusive presence of ent-CDP synthases in the same branch underscores the distinct evolutionary conservation of ent-CDP synthases in monocots (Fig. 2). The CPS in the chromosome 2 cluster has not been characterized yet and we propose to name it HvCPS2. HvCPS2 shares high similarity to TaCPS2, a (+)-CDP synthase, and belongs to the same branch as OsCPS4, a syn-CDP synthase, and TaCPS1, an ent-CDP synthase. Thus, although these data support a role of HvCPS2 in specialized diterpenoid metabolism, they do not allow us to predict its actual biochemical activity with high confidence.

The kaurene synthase-like of the chromosome 2 cluster was already identified previously and named HvKSL4 (Li et al., 2016). In the phylogenetic tree comprising other monocot KSL enzymes (Fig. 2), it is in the same branch as TaKSL1, TaKSL4 and OsKSL4. The substrate of TaKSL1 and TaKSL4 is (+)-CDP (Zhou et al., 2012), while that of OsKSL4 is syn-CDP (Otomo et al., 2004). In the neighboring branch are TaKSL2 and TaKSL3. The function of TaKSL3 is unknown but TaKSL2 also uses (+)-CDP as substrate (Zhou et al., 2012). The clear separation from KSL enzymes that use ent-CDP as substrate, including the barley entkaurene synthase (HvKS), indicates that HvKSL4 most likely uses either (+)-CDP or synCDP as substrate.

\section{HvCPS2 is a (+)-CDP synthase and HvKSL4 produces a cleistanthane-type backbone}

To determine the biochemical activity of HvCPS2, we expressed it in yeast using our Golden Gate yeast cloning system (Scheler et al., 2016) together with RoMiS, the miltiradiene synthase from rosemary (Rosmarinus officinalis) (Brückner et al., 2014), with CcKS, an ent- 
193 kaurene synthase from coffee (Coffea canephora), or with HvKSL4. Co-expression with

194 RoMiS yielded the expected diterpene product (miltiradiene), whereas no ent-kaurene could 195 be detected with CcKS, demonstrating that HvCPS2 produces (+)-CDP (Fig. 3). Co196 expression of HvCPS2 and HvKSL4 in yeast yielded a novel product with a molecular ion of 197272 (Fig. 3), indicating that it is a diterpene olefin. Besides this major product, several much 198 more minor products could also be detected. When expressing truncated versions of 199 HvCPS2 and HvKSL4 together with a cytosolic geranylgeranyl diphosphate synthase 200 (GGPPS) and a truncated version of hydroxymethylglutaryl CoA-reductase (tHMGR) in 201 Nicotiana benthamiana, the same product could be detected (Fig. S1). Since there was no 202 significant match in the NIST database (Mass Spectrometry Data Center, 203 http://chemdata.nist.gov), we purified the main product and determined its structure by 204 nuclear magnetic resonance (NMR) spectroscopy (see Table S4). The product was 205 determined to have a cleistanthane backbone, with two double bonds in the C-ring at 206 positions C8-C9 and C12-C13, a methyl group attached to C13 and an ethyl group attached 207 to $\mathrm{C} 14$ in the a-configuration (Fig. 3). Cleistanthanes constitute a relatively small group of 208 diterpenes that occur in some plants and fungi [see for example: (Kaufman et al., 1987; Riehl 209 and Pinto, 2000; Shiono et al., 2010; Zheng et al., 2018)]. We could not find published 210 reports of the exact same structure and we therefore named it hordediene (alternatively: 211 cleistantha-8(9),12(13)-diene).

212

\section{Phylogenetic analysis of the CYPs in the chromosome 2 cluster}

214 Of the eight CYP-encoding genes in the chromosome 2 cluster, only five are expressed at 215 significant levels and display an expression pattern similar to that of HVCPS2 and HVKSL4. 216 Furthermore in the latest annotation of the barley genome, two of these genes merged into a 217 single one so that only four CYP-encoding genes can be considered in the current version of 218 the barley genome (Table 1). A phylogenetic analysis of these sequences shows that three 219 of them are most similar to OsCYP99A2 and to OsCYP99A3 from rice (see Fig. S2 and 220 Table S5). Although no biochemical function could be determined for OsCYP99A2 yet, 221 OsCYP99A3 plays a role in the biosynthesis of momilactones by oxidizing syn-labdane 222 related diterpenes - syn-pimaradiene and syn-stemodene - at the C19 position to generate a 223 carboxylic acid function (Wang et al., 2011). Interestingly, OsCYP99A2 and OsCYP99A3 are 224 located in the same tandem cluster next to OsCPS4 and OsKSL4, a situation highly 225 reminiscent of the barley cluster presented here (Shimura et al., 2007).

226 The fourth CYP shares strongest similarity to enzymes of the CYP89 clan, with the closest 227 homolog in Arabidopsis thaliana being CYP89A2 (AT1G64900), whose biochemical function 228 is unknown yet. The most closely related protein sequences in the databases are homologs 
229

230

231

232

233

234

235

236

237

238

239

240

241

242

243

244

245

246

247

248

249

250

251

252

253

254

255

256

257

258

259

260

261

262

263

264

265

from other crops, e.g. Triticum aestivum or Setaria viridis, but these are of unknown function as well. The assigned identification for this CYP is CYP89E31.

\section{Characterization of HvCYP89E31}

We first focused on the characterization of HvCYP89E31 by expressing it in yeast. We cloned a yeast optimized sequence in a vector together with HvCPS2 and HvKSL4 and in addition with the cytochrome P450 reductase from Arabidopsis. Analysis of the extracts by gas chromatography couple to electron ionization mass spectrometry (GC/El-MS) showed the presence of two additional peaks, with a molecular $\mathrm{m} / \mathrm{z}$ of 270 (product 2) and 286 (product 3), respectively (Fig. 4). These masses indicate one and two additional degrees of oxidation. Next, we also isolated microsomes from a yeast strain expressing CYP89Ax and performed in vitro assays with hordediene as a substrate. GC-MS analysis of the extracts from this reaction showed the same products that are produced by yeast expressing all three genes (Fig. 4). This conclusively demonstrates that the new products detected are directly derived from hordediene. We also expressed those three genes in $N$. benthamiana as described above for HvCPS2 and HvKSL4 and found the exact same products present in hexane extracts (Fig. S1). The products were purified from a large scale yeast culture and their structure determined by NMR (Tables $\mathbf{S 6}$ and S7). Compound 2 has an aromatized Cring whereas compound 3 has a hydroxyl group on position 11 (Fig. 4). We propose to name these compounds hordetriene (2) and 11-hydroxy-hordetriene (3).

\section{Hordetriene and 11-hydroxy-hordetriene are present in barley roots infected with $B$.} sorokiniana

To determine if the diterpene products identified in yeast and $N$. benthamiana by metabolic engineering are also produced in barley plants, we infected barley roots with the pathogen $B$. sorokiniana, or with the beneficial fungus Serendipita vermifera (syn. Sebacina vermifera) or with both as described in Sarkar et al. (2019). Hexane extracts from the roots were then analyzed by GC-MS and compared to an extract from a yeast strain expressing HvCPS2, HvKSL4 and CYP89E31 (Fig. 5). Whereas hordediene (1) could not be detected in any of the root extracts, 2 and $\mathbf{3}$ were detected in roots infected with $B$. sorokiniana or with $B$. sorokiniana and $S$. vermifera. In mock-infected roots or in roots infected with $S$. vermifera alone, smaller amounts of $\mathbf{3}$ could be detected compared to roots infected with $B$. sorokiniana, but 2 could not be detected. These results demonstrate that the diterpenoids produced by enzymes of the chromosome 2 cluster are indeed induced during fungal pathogen infection but not significantly by beneficial endophytic colonization, an observation consistent with the transcriptome data generated previously (Sarkar et al., 2019). 
Barley diterpenoid gene cluster

266 Detection/identification of diterpenoid phytoalexins induced by $B$. sorokiniana 267 infection

268 Given the presence of additional CYP enzymes in the barley chromosome 2 cluster, we 269 wondered whether further oxidized diterpenoids could be detected in barley roots infected 270 with B. sorokiniana. We thus performed untargeted LC-QToF-MS (negative mode) analysis 271 of extracts from the root and from the medium. Searching for masses corresponding to 272 additional oxidations of 3 (Fig. 4), i.e. 301.2, 317.2, 315.2 and 331.2, a number of peaks 273 could be detected with a strong increase in samples from roots and medium of plants 274 infected with B. sorokiniana (Fig. 6). By comparison, under mock control conditions this 275 accumulation was not observed. LC-TOF-MS with negative electrospray ionization detected $276[\mathrm{M}-\mathrm{H}]$ adducts of six major compounds of which two products with the monoisotopic neutral 277 mass or $316.21 \mathrm{Da}$ dominated. High enrichments were also observed for three compounds 278 with the monoisotopic formula mass $332.20 \mathrm{Da}$ and for one with $318.22 \mathrm{Da}$, indicating that 279 these main products carry 3 or 4 oxygen atoms. MS/MS spectra of these compounds imply a 280 diterpene character based on the fragment ions 269.19, 271.21, 287.20 and 301.1 (Fig. S3). 281 Neutral losses of 43.99 and 46.01 suggest the presence of lactones or carboxyl groups in all 282 six diterpenes. As well, compound 6 has an additional carbonyl group as indicated by a 283 neutral loss of 30.01 Da between the molecular ion and $\mathrm{m} / \mathrm{z} 287.203$.

284

285

\section{Discussion}

286

287

\section{Evolution and diversity of diterpenoid phytoalexins in monocots}

288 Since the discovery of diterpenoid phytoalexins in rice and the elucidation of their 289 biosynthesis, there has been an increasing number of reports on investigations of specialized 290 diterpenoid metabolism in monocots. This includes maize (Zea mays) (Schmelz et al., 2011; 291 Ding et al., 2020), switchgrass (Panicum virgatum) (Pelot et al., 2018; Muchlinski et al., 292 2021), and wheat (Triticum aestivum) (Wu et al., 2012; Zhou et al., 2012). In the Triticeae, 293 which comprise wheat, barley and rye (Secale cereale), despite the publication of a report 294 describing the characterization of wheat diterpene synthases, (Wu et al., 2012; Zhou et al., 295 2012), to the best of our knowledge no diterpenoid phytoalexins had been identified yet. Our 296 work shows that like maize and rice, barley is also able to produce diterpenoid phytoaelxins 297 when challenged with a pathogen. Thus, production of diterpenoid phytoalexins appears to 298 be a common feature of monocots. It is also noteworthy that the genes involved in the 299 biosynthesis of these compounds are frequently localized in clusters encoding diterpene 300 synthases (CPS and KSL) as well as CYPs or in the case of rice a short chain 301 dehydrogenase reductase (OsMAS) (Shimura et al., 2007; Ding et al., 2020; Muchlinski et 302 al., 2021). Clusters of genes involved in specialized metabolism are encountered in plants 
303

304

305

306

307

308

309

310

311

312

313

314

315

316

317

318

319

320

321

322

323

324

325

326

327

328

329

330

331

332

333

334

335

336

337

338

339

and typically consist of tandem duplicated copies of one or more gene families (Nützmann et al., 2016). The molecular mechanisms driving the formation and evolution of these clusters are still enigmatic, but the physical association and duplication of genes offer a number of potential advantages. First, physical association means that possible toxic intermediates due to mutation or loss of one of the genes are less likely to accumulate. Second, the presence of multiple copies of highly similar genes provides opportunities for gene rearrangements and independent evolution, thereby opening the door to rapid chemical innovations. The capacity to evolve novel defenses rapidly constitutes a key evolutionary adaptation in the arms race against pests and pathogens.

Despite the relatedness of wheat and barley, the characterization of wheat diterpene synthases indicates that none of them can produce the cleistanthane backbone identified here (Awika, 2011). This is additional evidence that the gene clusters allow for rapid evolution of enzyme function and chemical diversification.

A search for regions in rice that are syntenic to the barley cluster on chromosome 2 using the SynFind tool (Tang et al., 2015) was unsuccessful (data not shown). This could be due to the fact that this chromosomal region is subject to frequent rearrangements. Nonetheless, in a publication investigating the synteny between rice and barley (Thiel et al., 2009), much of barley chromosome 2 was found to be syntenic with rice chromosome 4, which is where the main cluster for momilactone biosynthesis is located. Thus, it is possible that the evolution of this genomic cluster predates the divergence between Triticeae and rice.

\section{Hordediene: an unprecendented diterpene backbone in grasses}

HvKSL4 catalyzes the cyclization of (+)-CPP to hordediene, a cyclization reaction which, to the best of our knowledge, has not been reported previously, at least not in monocots. Hordediene belongs to the cleistanthane group of labdane-related diterpenes, which is characterized by the presence of an ethyl group attached to $\mathrm{C} 17$, instead of $\mathrm{C} 13$ as in pimaradiene. In the cyclization pathway we propose, after the initial dephosphorylation, the first electron migrations lead to the formation of the pimaradienyl cation (Fig. S4). At this point the pathway diverges from the pimaradiene cyclization via capture of a proton from C9 by the $\mathrm{C} 14-\mathrm{C} 15$ double bond of pimaradienyl. This results in formation of the C8-C9 double bond and the $\mathrm{C} 14$ carbocation. A hydride shift from $\mathrm{C} 17$ to $\mathrm{C} 14$ would then allow the migration of the ethyl group to $\mathrm{C} 17$ and consequently result in the presence of carbocation at C13. Resolution of this cation by proton loss from $\mathrm{C} 12$ would then lead to hordediene.

$$
\text { A survey of the literature on cleistanthane diterpenoids reveals a modest number of reports }
$$
(65 in Web of Science as of May 2021), with occurrence either in plants or fungi. Many of the cleistanthanes reported are of the ent- configuration, such as Fimbricalyxoid A from Strophioblachia fimbricalyx (Cheng et al., 2016) but some of normal (+) configuration, like 
340 hordediene, have also been described, such as zythiostromic acids (Ayer and Khan, 1996).

341 There is little information on the biological function of these diterpenoids, although in some cases

342 anticancer activity in the $\mu \mathrm{M}$ range could be determined (Cheng et al., 2016).

343

344 Production and potential role of diterpenoid phytoalexins in barley

345 We characterized three genes from the cluster (HvCPS2, HvKSL4 and HvCYP89E31) and

346 showed that co-expression of these three genes results in the production of two major

347 products, hordetriene and 11-hydroxy-hordetriene. The fact that we could detect both of

348 these products in barley roots infected with $B$. sorokiniana, strongly supports a role of this

349 cluster in the production of diterpenoid phytoalexins and in the defense reaction of barley.

350 LC-MS analysis indicated the presence of further oxidized diterpenoids, however at this

351 stage we were not able to isolate and purify sufficient quantity of these compounds for

352 structural elucidation. Thus it remains to be determined whether these are also derived from

353 the same diterpene backbone as compounds 2 and 3. The fact that no other diterpene

354 synthase is induced by $B$. sorokinianasorokiniana in our transcriptome data argues in favor of

355 this hypothesis. At this stage, we can only speculate on the biological activity of these

356 compounds. Their biosynthesis is only minimally induced by $S$. vermifera, but very strongly

357 by the pathogenic fungus $B$. sorokiniana (Sarkar et al., 2019). Whether the induction is

358 specific to $B$. sorokiniana or is a general response to infection by pathogens remains to be

359 determined. Interestingly, in a recent report on the metabolic profiling of barley plants

360 infected with Fusarium graminearum, which causes head blight, two diterpenoids with

361 masses of 302.2 and 318.2 were the most strongly induced compounds (respectively 32 and

36222 fold change) (Karre et al., 2017). They were annotated as neoabietic and 7-

363 hydroxykaurenoic acid respectively, although there was no formal identification of these

364 compounds. We suspect that these compounds also belong to the diterpenoid group that we

365 identified, which would suggest that they are not induced specifically by $B$. sorokiniana.

366 Availability of larger amounts of pure compounds in the future will allow us to perform

367 bioassays and determine their potential antimicrobial activity. Of relevance to their biological

368 function is the fact that these compounds are for the most part secreted into the medium by

369 the roots. Since they are present at a low basal level in non-infected plants, it is likely that

370 their presence in the rhizosphere could influence the composition of the root microbiome.

371 There is already evidence of specialized metabolites secreted by the roots that impact the

372 composition of the microbiome (Massalha et al., 2017; Huang et al., 2019; Murphy et al.,

373 2021). Conversely, specific members of the microbial community can induce secretion of

374 specialized metabolites by the roots (Massalha et al., 2017), suggesting a complex network

375 of signals and effectors between the microbial community and the plant in the rhizosphere. 


\section{Barley diterpenoid gene cluster}

376 Generating barley plants mutated in HvCPS2 or HvKSL4 by CRISPR-Cas gene editing will

377 allow us to address these questions in this important crop species in the future.

378

379 Materials and Methods

380

381

\section{Plant growth and fungal inoculations}

382

Barley seeds (Hordeum vulgare L. cv Golden Promise) were sterilized in $70 \%$ ethanol for 1 min, followed by washing with sterile distilled water and $1.5 \mathrm{~h}$ incubation in $12 \%$ sodium hypochloride under continuous shaking. After 3 times $30 \mathrm{~min}$ washing, the seeds were placed on wet filter paper in darkness and at room temperature for 4 days for germination. Four seedlings were transferred to 1/10 PNM (Plant Nutrition Medium, pH 5.7) (Wawra et al., 2016 ) in sterile glass jars and grown in a day/night cycle of $16 / 8 \mathrm{~h}$ at $22 / 18{ }^{\circ} \mathrm{C}, 60 \%$ humidity under $108 \mu \mathrm{mol} \mathrm{m}^{-2} \mathrm{~s}^{-1}$ light intensity.

Bipolaris sorokiniana (ND90Pr) and Serendipita vermifera (MAFF305830) were used in this study. Bs was propagated on modified CM medium with 1.5\% agar and Sv on MYP medium with $1.5 \%$ agar in the dark at $28{ }^{\circ} \mathrm{C}$ for 21 days and 14 days before inoculation respectively. $B s$ conidia and Sv mycelial were collected according to the procedures which were described in (Sarkar et al., 2019). Barley roots were inoculated with $3 \mathrm{ml}$ of either $S v$ mycelium $(2 \mathrm{~g} / 50 \mathrm{ml})$, Bs conidia (5000 spores/ml) or a 1:1 mixture of the two fungi per jar for 6 days. Sterile water was used as a mock treatment. Roots washed thoroughly and the corresponding medium were collected and snap-frozen in liquid nitrogen for extraction of metabolites.

398

\section{qRT-PCR}

400 RNA isolation from roots was performed using the Spectrum Plant Total RNA kit (Sigma-

401 Aldrich). The complementary DNA (cDNA) was synthesized using ProtoScript II First Strand 402 cDNA Synthesis Kit (New England Biolabs) following the manufacturer's instructions with 403 primer $\mathrm{d}(\mathrm{T})_{23} \mathrm{VN}$. Quantitative real-time PCR was performed in triplicates using 10-20 $\mathrm{ng}$ 404 cDNA as template and gene specific primer pairs shown in Table S8 in CFX Connect Real405 Time PCR System (Bio-Rad). The PCR conditions were $95 \square^{\circ} \mathrm{C}$ for $15 \square \mathrm{min} ; 40$ cycles of 95 $406{ }^{\circ} \mathrm{C}$ for $15 \mathrm{~s}, 56 \square{ }^{\circ} \mathrm{C}$ for $30 \square \mathrm{s} ; 95^{\circ} \mathrm{C}$ for $10 \mathrm{~s}$. The melting curve was measured from $65^{\circ} \mathrm{C}$ to $40795{ }^{\circ} \mathrm{C}$ with a step of $0.1 \square^{\circ} \mathrm{C}$ per second. Relative expression of targeted genes was 408 calculated using delta Ct method (Livak and Schmittgen, 2001) and barley ubiquitin genes as 409 references (Deshmukh et al., 2006).

410

\section{Phylogenetic analysis}


412 Amino acid sequences (Tables S2, S3 and S5) were aligned and phylogenetic trees were

413 generated using MEGA X (Kumar et al., 2018). ClustalW was used for the alignment and the

414 maximum likelihood method with a bootstrap of 1,000 for the phylogenetic tree. For the other

415 parameters, default settings were used.

416

417 Heterologous expression of diterpenes in yeast

418 Plasmids containing GGPPS and ATR1 were kindly provided by colleagues in the group and 419 have been described previously (Scheler et al., 2016). Codon-optimized DNA sequences of 420 HvCPS2, HvKSL4 and HvCYP89E31 were synthesized by Thermo Fisher Scientific Inc. for 421 yeast expression. Each gene was further cloned into Golden Gate compatible yeast 422 expression level 1 vector, together with a synthetic galactose-inducible promoter and a 423 terminator. Different gene combinations were finally assembled into one yeast expression 424 level $\mathrm{M}$ vector by a 50 cycle restriction-ligation reaction with Bpil and T4-Ligase.

425 Constructs were then transformed into S. cerevisiae strain INVSc1 (Thermo Fisher Scientific 426 Inc.) and plated out onto uracil-free (Ura-) selection medium (1 $\square \mathrm{g} \square \mathrm{l}^{-1}$ Yeast Synthetic Drop427 out Medium Supplements without uracil (Sigma-Aldrich), 6.7 $\square \mathrm{g} \square \mathrm{l}^{-1}$ Yeast Nitrogen Base with 428 Amino Acids (Sigma-Aldrich) and 20 $\square \mathrm{g} \square \mathrm{I}^{-1}$ Micro Agar (Duchefa Biochemie)). Three positive 429 colonies were picked and inoculated into $5 \square \mathrm{ml}$ yeast extract-peptone-dextrose (YPD) 430 medium (20 $\square \mathrm{g} \square \mathrm{I}^{-1}$ tryptone and $10 \square \mathrm{g} \square \mathrm{I}^{-1}$ yeast extract) containing $2 \%$ of glucose and grown 431 for $24 \square \mathrm{h}$ with shaking at $30 \square^{\circ} \mathrm{C}$. To induce protein expression, the cell pellet was 432 resuspended in fresh YPD medium containing 2\% galactose. After another 24 $\square \mathrm{h}$ of growth, 433 the whole culture was extracted with $2 \square \mathrm{ml} n$-hexane.

434

435 Transient expression in Nicotiana benthamiana

436 Transit peptides of protein HvCPS2 and HvKSL4 were predicted by two online tools, ChloroP 4371.1 (http://www.cbs.dtu.dk/services/ChloroP/) and LOCALIZER (http://localizer.csiro.au/). 438 Truncated sequences without the predicted transit peptides of these two genes were 439 generated by PCR reactions using designed primers and subsequently sequenced. The 440 cDNAs of HMG reductase, GGPPS in plasmids have been described previously (Scheler et 441 al., 2016; Yadav et al., 2019). The HMG reductase, GGPPS, trHvCPS2, trHvKSL4 and 442 HvCYP89E31 were cloned into T-DNA vectors (binary vector pL1F-1) driven by the $35 \mathrm{~S}$ 443 promoter and flanked by the Ocs terminator (Weber et al., 2011). The resulting T-DNA 444 plasmids were transformed into Agrobacterium tumefaciens strain GV3101::pMP90 and 445 plated out onto LB agar plates with appropriate antibiotics. Bacteria were harvested and 446 resuspended in infiltration medium (10 mM MgCl, $10 \mathrm{mM} \mathrm{MES,} 20 \mu \mathrm{M}$ acetosyringone, $447 \mathrm{pH}=5.6$ ) after $48 \mathrm{~h}$ inoculation at $28 \square^{\circ} \mathrm{C}$. To co-infiltrate several genes, each bacteria 448 suspension was diluted to a final $\mathrm{OD}_{600}$ of 0.4 , then all strains were mixed equally to an 
449

450

451

452

453

454

455

456

457

458

459

460

461

462

463

464

465

466

467

468

469

470

471

472

473

474

475

476

477

478

479

480

481

482

483

484

485

appropriate volume for infiltration. The suspension was infiltrated into the abaxial side of several leaves in three individual 4-week-old $N$. benthamiana plants using a syringe without needle. After treatment, the plants were cultivated in a climate controlled phytochamber for 4 days. Three leaf discs ( $9 \mathrm{~mm}$ diameter) per infiltrated spot were harvested and extracted by 2 $\mathrm{ml} n$-hexane, followed by drying down under nitrogen flow and GC-MS analysis.

\section{Microsome isolation and in vitro enzyme assay}

A protocol from the literature with slight modification was used for microsome isolation (Urban et al., 1997; Scheler et al., 2016). The construct carrying HVCYP89E31 and ATR1 were transformed into yeast strain INVSc1. A single positive colony was picked to inoculate $5 \square \mathrm{ml}$ of Ura-medium with $2 \%$ glucose and grown for $24 \square \mathrm{h}$ at $30 \square{ }^{\circ} \mathrm{C}$ with shaking. The culture was then used to inoculate $100 \square \mathrm{ml}$ of Ura-medium with $2 \%$ glucose in a $500 \square \mathrm{ml}$ flask at $30 \square^{\circ} \mathrm{C}$ for $24 \square \mathrm{h}$. The cells were then collected by centrifugation, resuspended in $100 \square \mathrm{ml}$ fresh YPD medium with $2 \%$ galactose to induce protein expression and inoculated under shaking for another $24 \square \mathrm{h}$ at $30 \square^{\circ} \mathrm{C}$. All the following steps were carried out at $4 \square^{\circ} \mathrm{C}$. The cells were harvested by centrifugation and resuspended in $30 \square \mathrm{ml}$ of pre-chilled TEK buffer $(50 \square \mathrm{mM}$ Tris- $\mathrm{HCl} \mathrm{pH} 7.5,1 \square \mathrm{mM}$ EDTA, $100 \square \mathrm{mM} \mathrm{KCl})$, centrifuged again and resuspended in $2 \square \mathrm{ml}$ TES buffer ( $50 \square \mathrm{mM}$ Tris- $\mathrm{HCl} \mathrm{pH} \mathrm{7.5,600 \square mM} \mathrm{sorbitol,} 10 \square \mathrm{g}^{-1} l^{-1} \mathrm{BSA}$, $1.5 \square \mathrm{mM} \beta$-mercaptoethanol) and transferred to a $50 \square \mathrm{ml}$ tube. Acid-washed autoclaved $450-$ $600 \square \mu \mathrm{m}$ diameter glass beads were added into the tube until the surface of the cell suspension are reached. The suspension was shaken vigorously by hand for $1 \square \mathrm{min}$ and returned back to ice for $1 \square \min$. This step was repeated four times. The glass beads were washed by $5 \square \mathrm{ml}$ TES buffer three times, and the supernatant was collected and combined to a new tube, followed by centrifugation at $7,500 \square \mathrm{g}$ for $10 \square \mathrm{min}$. The supernatant was transferred to ultracentrifugation tubes and centrifuged for $2 \square \mathrm{h}$ at $100 \square 000 \square \mathrm{g}$. The pellet was gently washed successively with $5 \square \mathrm{ml}$ TES and $2.5 \square \mathrm{ml}$ TEG buffer (50 $\square \mathrm{mM}$ Tris- $\mathrm{HCl}$ $\mathrm{pH} 7.5,1 \square \mathrm{mM}$ EDTA and $30 \%$ glycerol) after the supernatant was removed, then transferred to a Potter homogenizer with a spatula. $2 \mathrm{ml}$ TEG buffer was added to the homogenizer and the pellet was carefully homogenized. $100 \mu \mathrm{l}$ aliquots were transferred to $1.5 \square \mathrm{ml}$ microtubes and stored at $-80 \square^{\circ} \mathrm{C}$ until used.

In vitro CYP enzyme assays were performed in a $600 \square \mu$ l reaction volume, containing $40 \square \mu l$ of microsome preparation, $100 \square \mu \mathrm{M}$ substrate, $1 \square \mathrm{mM} \mathrm{NADPH}, 50 \square \mathrm{mM}$ sodium phosphate $\mathrm{pH}$ 7.4. The solution was incubated at $30 \square^{\circ} \mathrm{C}$ for $2 \square \mathrm{h}$ with gentle shaking. Products were extracted with $1 \square \mathrm{ml} n$-hexane under strong agitation (vortex). After centrifugation, the organic phase was collected, then dried under a $\mathrm{N}_{2}$ stream and resuspended in $100 \square \mu \mathrm{l} n$ hexane for GC-MS analysis. 


\section{Purification of diterpenes by silica gel column chromatography or SPE}

487 For the purification of hordediene, 1 I of yeast culture was grown and extracted with 1 I $n$ 488 hexane. The raw extracts were dried in a rotary evaporator and resuspended in $4 \mathrm{ml} \mathrm{n}$ 489 hexane, then loaded into two properly conditioned SiOH SPE cartridges (500 mg, 490 MACHEREY-NAGEL). The cartridges were then washed with $2 \mathrm{ml}$-hexane. The 491 breakthrough and washing fraction were collected and combined. After drying down under 492 nitrogen stream, an aliquot was measured by GC-MS to check the purity of the product and 493 the rest, with an amount of around $2 \mathrm{mg}$ was used for NMR structure elucidation.

494 Hordetriene and 11-hydroxy-hordetriene were first extracted from three liters of yeast culture. 495 After concentration, the raw extracts were dissolved in $4 \mathrm{ml} n$-hexane and loaded into a pre496 conditioned self-packed silica gel column $(5 \mathrm{~g}, 15 \mathrm{~mm} \times 100 \mathrm{~mm})$. The column was then 497 eluted by $n$-hexane and successively by 99:1, 98:2, 97:3, 96:4, 96:5 $n$-hexane: ethyl acetate 498 solutions. The volume of each elution solution was $10 \mathrm{ml}$ but the elution was separately 499 collected in five $2 \mathrm{ml}$ microtubes. An aliquot of each fraction was measured by GC-MS and 500 the fractions with the same product were combined and then used for NMR structure 501 elucidation. The yield of hordetriene and 11-hydroxyhordetriene was around $0.5 \mathrm{mg}$.

502

503

Nuclear magnetic resonance (NMR) conditions

$504 \mathrm{H},{ }^{13} \mathrm{C}, 2 \mathrm{D}\left({ }^{1} \mathrm{H},{ }^{1} \mathrm{H}\right.$ gDQCOSY; ${ }^{1} \mathrm{H},{ }^{1} \mathrm{H}$ zTOCSY $;{ }^{1} \mathrm{H},{ }^{1} \mathrm{H}$ ROESYAD; ${ }^{1} \mathrm{H},{ }^{13} \mathrm{C}$ gHSQCAD; $505{ }^{1} \mathrm{H},{ }^{13} \mathrm{C}$ gHMBCAD), selective ( ${ }^{1} \mathrm{H},{ }^{1} \mathrm{H}$ zTOCSY1D; ${ }^{1} \mathrm{H},{ }^{1} \mathrm{H}$ ROESY1D), and band 506 selective $\left({ }^{1} \mathrm{H},{ }^{13} \mathrm{C}\right.$ bsHMBC) NMR spectra were measured with an Agilent VNMRS 507600 instrument at $599.83 \mathrm{MHz}\left({ }^{1} \mathrm{H}\right)$ and $150.84 \mathrm{MHz}\left({ }^{13} \mathrm{C}\right)$ using standard 508 CHEMPACK 8.1 pulse sequences implemented in the VNMRJ 4.2A spectrometer 509 software. TOCSY mixing time: $80 \mathrm{~ms}$; ROESY mixing time: $300 \mathrm{~ms}$; HSQC optimized

510 for ${ }^{1} \mathrm{~J}_{\mathrm{CH}}=146 \mathrm{~Hz}$; HMBC optimized for ${ }^{n} \mathrm{~J}_{\mathrm{CH}}=8 \mathrm{~Hz}$. All spectra were obtained with $511 \quad \mathrm{C}_{6} \mathrm{D}_{6}+0.03 \% \mathrm{TMS}$ as solvent at $+25^{\circ} \mathrm{C}$. Chemical shifts were referenced to internal

512 TMS $\left(\delta{ }^{1} \mathrm{H}=0 \mathrm{ppm}\right)$ and internal $\mathrm{C}_{6} \mathrm{D}_{6}\left(\delta{ }^{13} \mathrm{C}=128.0 \mathrm{ppm}\right)$.

513

514 Metabolites extraction from barley roots and PNM medium

$515100 \mathrm{mg}$ (fresh weight) of frozen and cryo-ground root matter was extracted using $900 \mu \mathrm{L}$ 516 dichloromethane/ethanol $(2: 1, \mathrm{v} / \mathrm{v})$ and $100 \mu \mathrm{l}$ hydrochloric acid solution ( $\mathrm{pH}$ 1.4). Extraction 517 and duplicate removal of hydrophilic metabolites was achieved by 1 min FastPrep bead 518 milling (FastPrep24, MP Biomedicals) followed by phase separation during centrifugation. 519 For extraction $1.6 \mathrm{~mL}$ wall-reinforced cryo-tubes (Biozyme) each containing steel and glass 520 beads were used. The upper aqueous phase was discarded and replaced for a second round 521 of bead mill extraction/ centrifugation. Thereafter, the aqueous phase was removed and the 
522 lower organic phase was collected. Subsequently $600 \mathrm{uL}$ tetrahydrofuran (THF) was used for

523 exhaustive extraction (FastPrep). After centrifugation the organic THF extract was combined

524 with the first extract and dried under a stream of $\mathrm{N}_{2}$.

525 Root exudates were extracted from $60 \mathrm{~mL}$ of gelrite media. For this, the gel was distributed 526 into two $50 \mathrm{ml}$ Falcon tubes. To each tube $4 \mathrm{~g}$ of $\mathrm{NaCl}$ and $3 \mathrm{~mL}$ ethyl acetate were added.

527 The tubes were thoroughly shaken by hand and centrifuged. The upper phase (organic 528 extract) was collected before fresh ethyl acetate was added for another two consecutive 529 extractions. The combined extracts of three extraction rounds were combined and dried in a 530 stream of $\mathrm{N}_{2}$.

531

532 GC-MS

533 Dried extracts were suspended in $200 \mu \mathrm{n}$-hexane. The analysis of yeast and plant extracts 534 was carried out using a Trace GC Ultra gas chromatograph (Thermo Scientific) coupled to an 535 ATAS Optic 3 injector and an ISQ single quadrupole mass spectrometer (Thermo Scientific) 536 with electron impact ionization. Chromatographic separation was performed on a ZB-5ms 537 capillary column $(30 \square \mathrm{m} \times 0.32 \square \mathrm{mm}$, Phenomenex) using splitless injection and an injection 538 volume of $1 \square \mu \mathrm{l}$. The injection temperature rose from $60 \square^{\circ} \mathrm{C}$ to $250 \square^{\circ} \mathrm{C}$ with $10 \square{ }^{\circ} \mathrm{C} \square \mathrm{s}^{-1}$ and 539 the flow rate of helium was $2 \square \mathrm{ml} \square \mathrm{min}^{-1}$. The GC oven temperature ramp was as follows: $54050 \square^{\circ} \mathrm{C}$ for $1 \square \min , 50$ to $300 \square^{\circ} \mathrm{C}$ with $7 \square \square^{\circ} \mathrm{C} \square \mathrm{min}^{-1}, 300-330 \square^{\circ} \mathrm{C}$ with $20 \square{ }^{\circ} \mathrm{C} \square \mathrm{min}^{-1}$ and $541330 \square^{\circ} \mathrm{C}$ for $5 \square \mathrm{min}$. Mass spectrometry was performed at $70 \square \mathrm{eV}$, in a full scan mode with $542 \mathrm{~m} / \mathrm{z}$ from 50 to 450 . Data analysis was done with the device specific software Xcalibur 543 (Thermo Scientific).

544

\section{RP-UPLC-ESI-MS/MS}

546 For UPLC-MS analysis dried extracts were suspended in $100 \mathrm{uL} 80 \%$ methanol/ 20\% water.

547 Separation of medium polar metabolites was performed on a Nucleoshell RP18 $(2.1 \times 150$ $548 \mathrm{~mm}$, particle size $2.1 \mu \mathrm{m}$, Macherey \& Nagel, GmbH, Düren, Germany) using a Waters 549 ACQUITY UPLC System, equipped with a Binary Solvent Manager and Sample Manager (20 $550 \mu$ sample loop, partial loop injection mode, $5 \mu \mathrm{l}$ injection volume, Waters GmbH Eschborn,

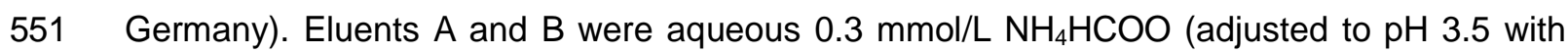
552 formic acid) and acetonitrile, respectively. Elution was performed isocratically for 2 min at $5 \%$ 553 eluent B, from 2 to 19 min with a linear gradient to $95 \%$ B, from 19-21 min isocratically at $55495 \% \mathrm{~B}$, and from $21.01 \mathrm{~min}$ to $24 \mathrm{~min}$ at $5 \% \mathrm{~B}$. The flow rate was set to $400 \mu \mathrm{min}^{-1}$ and the 555 column temperature was maintained at $40{ }^{\circ} \mathrm{C}$. Metabolites were detected by positive and 556 negative electrospray ionization and mass spectrometry.

557 Mass spectrometric analysis of small molecules was performed by MS-TOF-SWATH-MS/MS 558 (TripleToF 5600, AB Sciex GmbH, Darmstadt, Germany) operating in negative or positive ion 
559

560

561

562

563

564

565

566

567

568

569

570

571

572

573

574

575

576

577

578

579

580

581

582

583

584

585

586

587

588

589

590

591

592

593

594

595

mode and controlled by Analyst 1.7.1 software (AB Sciex $\mathrm{GmbH}$, Darmstadt, Germany). The source operation parameters were as follows: ion spray voltage, $-4500 \mathrm{~V} /+5500 \mathrm{~V}$; nebulizing gas, $60 \mathrm{psi}$; source temperature $600^{\circ} \mathrm{C}$; drying gas, 70 psi; curtain gas, 35 psi. TripleToF instrument tuning and internal mass calibration were performed every 5 samples with the calibrant delivery system applying $\mathrm{APCl}$ negative or positive tuning solution, respectively (AB Sciex GmbH, Darmstadt, Germany).

TripleToF data acquisition was performed in MS1-ToF mode and MS2-SWATH mode. For MS1 measurements, ToF masses were scanned between 65 and 1250 Dalton with an accumulation time of $50 \mathrm{~ms}$ and a collision energy of $10 \mathrm{~V}(-10 \mathrm{~V})$. MS2-SWATH-experiments were divided into 26 Dalton segments of $20 \mathrm{~ms}$ accumulation time. Together the SWATH experiments covered the entire mass range from 65 to 1250 Dalton in 48 separate scan experiments, which allowed a cycle time of $1.1 \mathrm{~s}$. Throughout all MS/MS scans a declustering potential of 35 (or $-35 \mathrm{~V}$ ) was applied. Collision energies for all SWATH-MS/MS were set to $35 \mathrm{~V}(-35)$ and a collision energy spread of $\pm 25 \mathrm{~V}$, maximum sensitivity scanning, and elsewise default settings.

\section{Acknowledgments}

This work was funded by grant TI 800/7-1 from the Deutsche Forschungsgemeinschaft (DFG) to AT and by grant ZU 263/11-1 to AZ. This project is part of the Priority Programme of the DFG SPP2125 "Deconstruction and Reconstruction of the Plant Microbiota, DECRyPT)." (https://ag-zuccaro.botanik.uni-koeln.de/decrypt).

\section{Conflict of interest}

The authors have no conflict of interest to declare.

\section{Author Contributions}

YL performed the LC-MS, GC-MS, yeast and $N$. benthamiana expression and gene expression analysis. GB provided supervision for LC-MS and data analysis. AS-H provided assistance for LC-MS sample preparation. AP performed the NMR measurements and analyses. UB supervised the yeast expression experiments. LM and AZ provided infected barley samples and transcriptomic data. AT and GB designed the project. AT designed and supervised the project. AT wrote the abstract, introduction, results and discussion. YL wrote the materials and methods, except the NMR part (AP) and LC-MS (GB). AT, YL and GB prepared the figures. All authors read and approved the manuscript.

\section{Tables}

Table 1 List of genes from the chromosome 2 diterpenoid phytoalexin cluster. 
bioRxiv preprint doi: https://doi.org/10.1101/2021.05.21.445084; this version posted May 22, 2021. The copyright holder for this preprint (which was not certified by peer review) is the author/funder, who has granted bioRxiv a license to display the preprint in perpetuity. It is made available under aCC-BY-NC-ND 4.0 International license.

Barley diterpenoid gene cluster

\begin{tabular}{|c|c|c|c|c|c|c|}
\hline \multicolumn{3}{|c|}{ Genome version } & \multirow{2}{*}{$\begin{array}{l}\text { Gene } \\
\text { status }\end{array}$} & \multirow{2}{*}{$\begin{array}{c}\text { Transcript } \\
\text { ID }\end{array}$} & \multirow[t]{2}{*}{ Protein ID } & \multirow[t]{2}{*}{ Name } \\
\hline $\begin{array}{l}\text { MorexV1 } \\
(2017)\end{array}$ & \begin{tabular}{|l} 
MorexV2 \\
$(2019)$
\end{tabular} & $\begin{array}{l}\text { MorexV3 } \\
(2021)\end{array}$ & & & & \\
\hline $2 \mathrm{Hr} 1 \mathrm{G} 004480$ & 2HG0081780 & 2HG0099280 & $\mathrm{FL}$ & AK252527.1 & & CYP99A66 \\
\hline $\begin{array}{l}2 \mathrm{Hr} 1 \mathrm{G} 004510 \\
2 \mathrm{Hr} 1 \mathrm{G} 004520\end{array}$ & 2HG0081840 & 2HG0099340 & Pseudo & & & \\
\hline 2Hr1G004530 & 2HG0081840 & 2HG0099350 & $\mathrm{FL}$ & & KAE8771735 & CYP99A67 \\
\hline 2Hr1G004540 & 2HG0081850 & 2HG0099360 & $\mathrm{FL}$ & AK370792 & & HvKSL4 \\
\hline 2Hr1G004550 & $\begin{array}{l}\text { 2HG0081860 } \\
\text { UnG0627890 } \\
\text { UnG0631950 }\end{array}$ & $\begin{array}{l}2 \mathrm{HG} 0099370^{\mathrm{a}} \\
2 \mathrm{HG} 0099420^{\mathrm{a}} \\
2 \mathrm{HG} 0099430^{\mathrm{a}}\end{array}$ & FL & AK369243 & & CYP89E31 \\
\hline NP & 2HG0081880 & 2HG0099470 & Pseudo & & & భCPS1 \\
\hline $2 \mathrm{Hr} 1 \mathrm{G} 004600$ & 2HG0081930 & 2HG0099550 & $\mathrm{FL}$ & & & CYP99A68 $^{\text {b }}$ \\
\hline $2 \mathrm{Hr} 1 \mathrm{G} 004610$ & 2HG0081980 & 2HG0099550 & $\mathrm{FL}$ & & & CYP99A68 $^{\text {b }}$ \\
\hline $\begin{array}{l}2 \mathrm{Hr} 1 \mathrm{G} 004640 \\
2 \mathrm{Hr} 1 \mathrm{G} 004650\end{array}$ & $\begin{array}{l}\text { 2HG0081890 } \\
\text { 2HG0082010 } \\
\text { 2HG0081930 } \\
\text { UnG0636400 }\end{array}$ & 2HG0099480 & $\mathrm{FL}$ & & & CYP99A68 $^{\text {b }}$ \\
\hline & 2HG0081920 & 2HG0099500 & Pseudo & & & భCPS2 \\
\hline $2 \mathrm{Hr} 1 \mathrm{G} 004620$ & 2HG0082000 & 2HG0099570 & $\mathrm{FL}$ & AK364238 & & HvCPS2 \\
\hline
\end{tabular}

596

597 Notes: (a) the amino acid sequences of these two genes are identical. The sequences only 598 differ in the 5'-UTR. (b) the amino acid sequences are identical except for one amino acid 599 change in 2Hr1G004600

600

601 Figures 


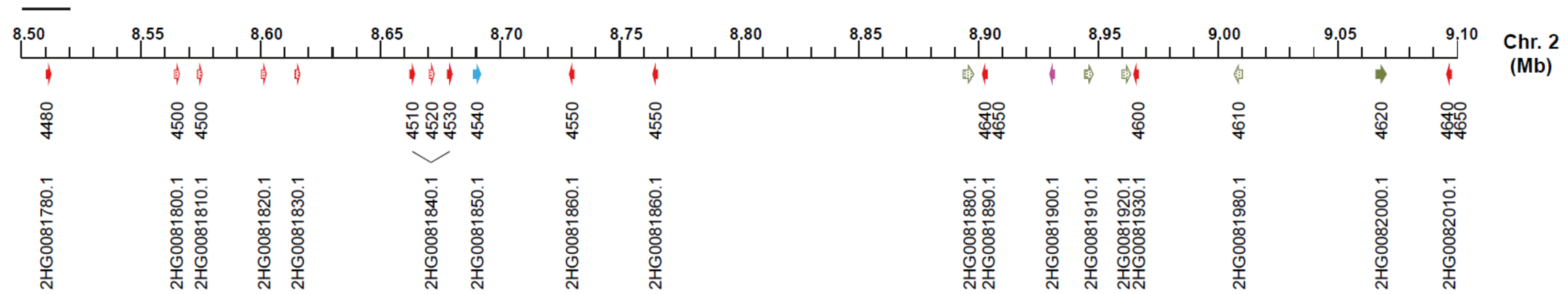

\section{DCYP}

Kaurene synthase-like

\Asparaginase

b) Pseudogenes
Copalyl diphosphate synthase

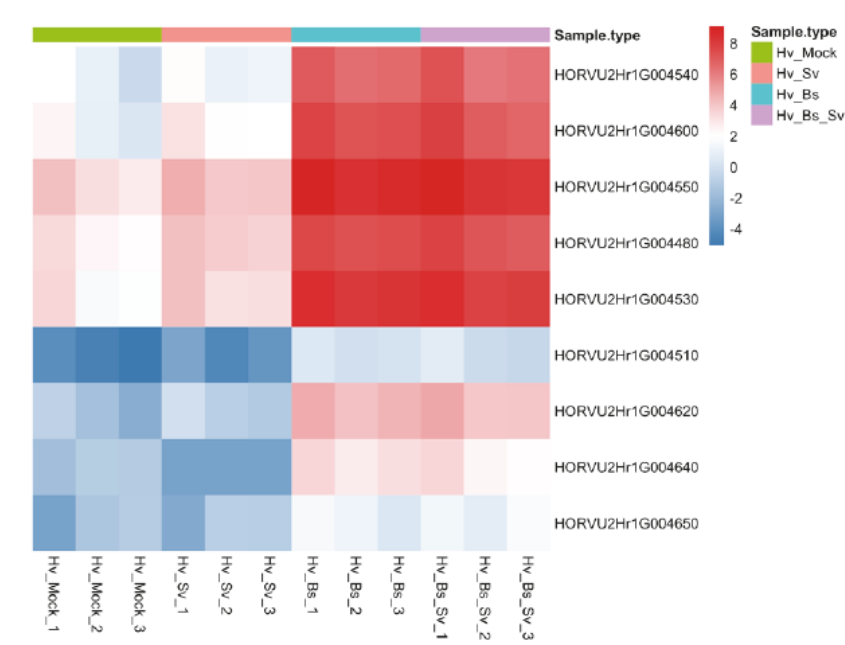

Figure 1. Overview of the barley chromosome 2 cluster for diterpenoid biosynthesis. The scale on top indicates the position on chromosome 2 based on the latest annotation of the barley genome (Monat et al., 2019). The genes are represented by arrows underneath the scale. The color code indicates to which gene family they belong and the dotted pattern the presence of a pseudogene. The first row of numbers below the scale indicates the last 4 digits of the gene ID according to MorexV1 gene models and the second row gives the gene identification in the MorexV2 version of the barley genome. The colored bars in the lower part represent gene expression values as log2-transformed FKPM values for genes that show differential gene expression ( |fold change| $>2$, data from Sarkar et al., 2019). Each square for a sample type represents data from a biological replicate. The samples types are indicated by the following color code: purple: barley root co-inoculated with $B$. sorokiniana and $S$. vermifera; turquoise blue: barley roots inoculated with $B$. sorokiniana; pink: barley roots inoculated with $\mathrm{S}$. vermifera; green: barley root mock inoculated. 
bioRxiv preprint doi: https://doi.org/10.1101/2021.05.21.445084; this version posted May 22, 2021. The copyright holder for this preprint (which was not certified by peer review) is the author/funder, who has granted bioRxiv a license to display the preprint in perpetuity. It is made available under aCC-BY-NC-ND 4.0 International license.

Barley diterpenoid gene cluster
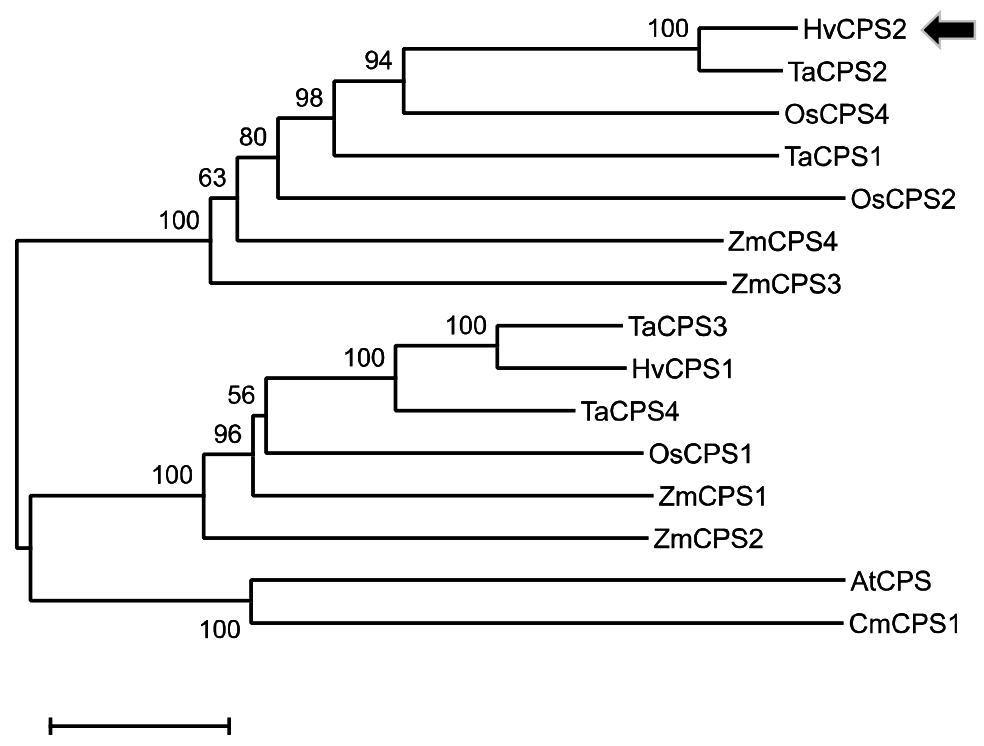

0.1

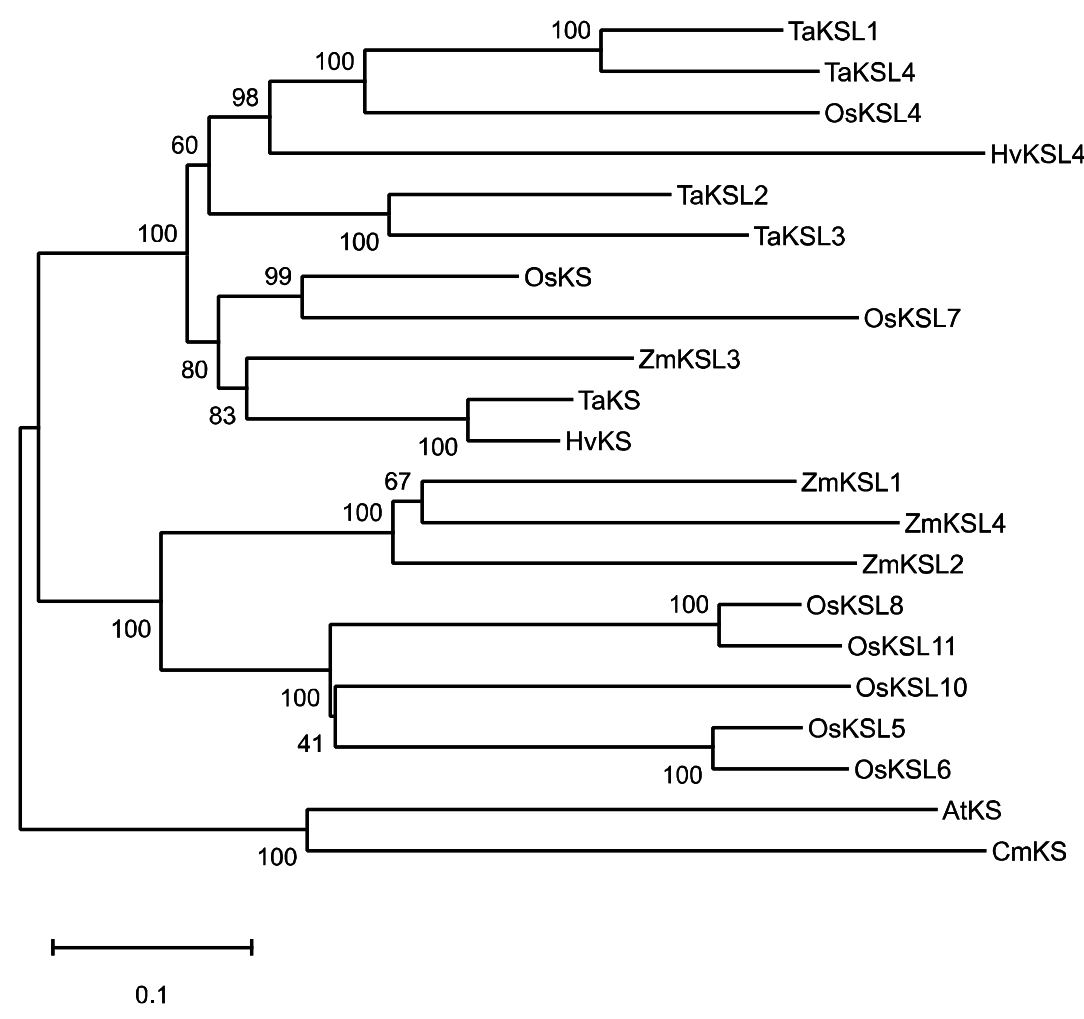

613 Figure 2. Phylogenetic analysis of HvCPS2 and HvKSL4. The sequences indicated were 614 aligned and processed with the MEGA X software (Kumar et al., 2018) with the maximum 615 likelihood method and 1000 bootstrap replications. The consensus trees are shown with the 616 bootstrap values for the individual branches shown. The HvCPS2 and HvKSL4 sequences 617 are indicated by grey arrows. The list of sequences used is provided in Tables S2 and S3. 
bioRxiv preprint doi: https://doi.org/10.1101/2021.05.21.445084; this version posted May 22, 2021. The copyright holder for this preprint (which

was not certified by peer review) is the author/funder, who has granted bioRxiv a license to display the preprint in perpetuity. It is made available under aCC-BY-NC-ND 4.0 International license.

Barley diterpenoid gene cluster
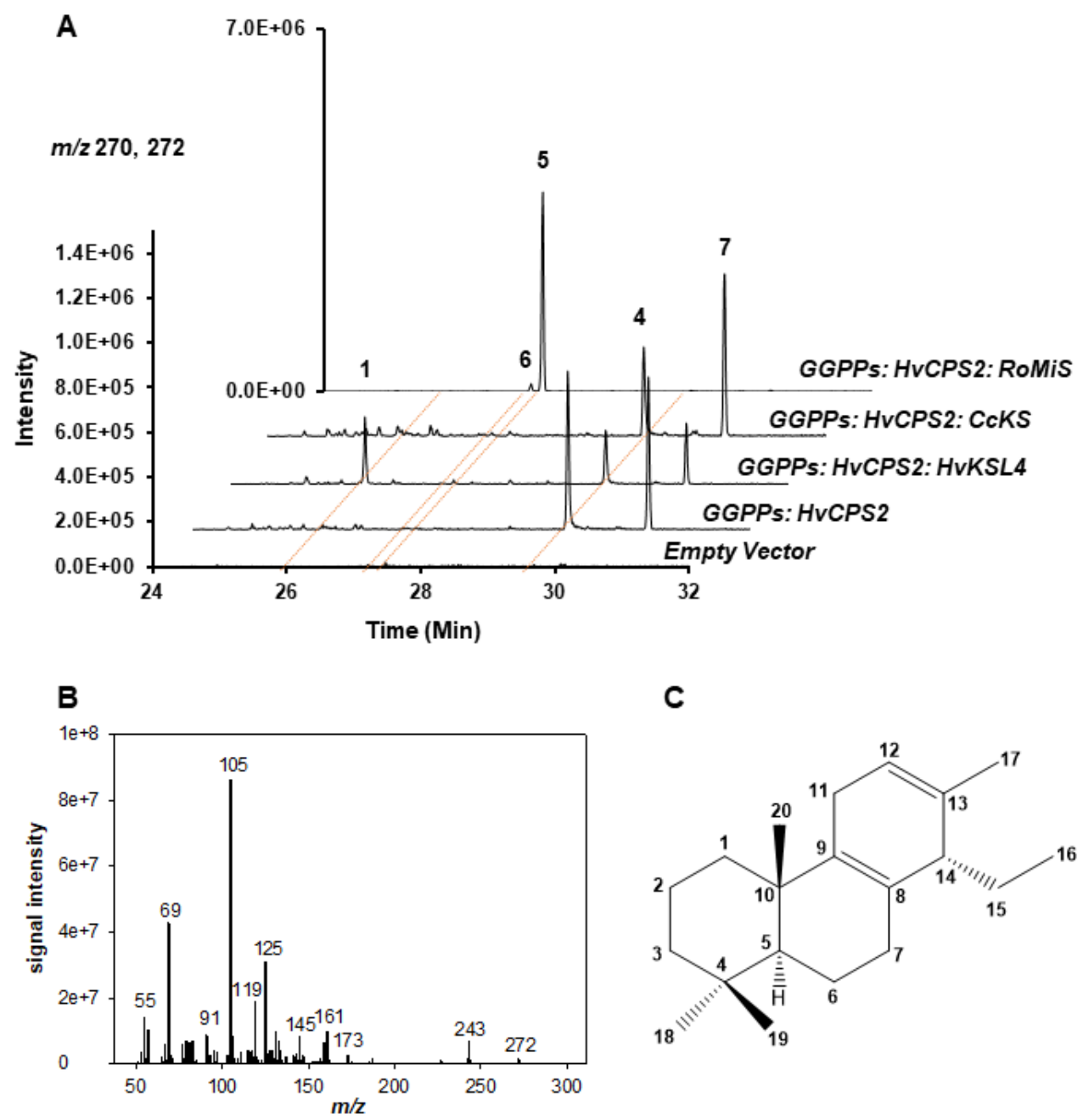

C

618

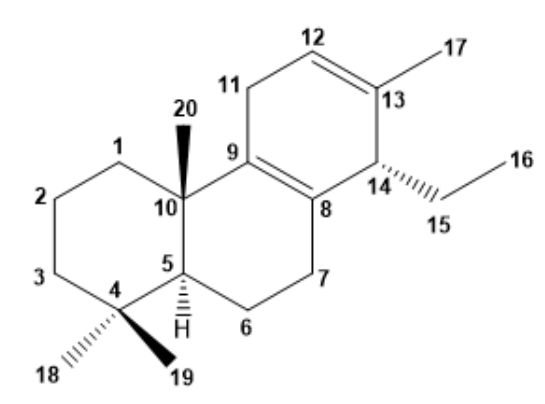

619

620 Figure 3. Expression of HvCPS2 and HvKSL4 in yeast. A. Selected ion $(\mathrm{m} / \mathrm{z} 270$ and 272$)$ GC-MS chromatograms of $n$-hexane extracts of yeast strains expressing the gene combinations indicated on the right. CcKS: ent-kaurene synthase from coffee (Coffea canephora); RoMiS, miltiradiene synthase from rosemary (Rosmarinus officinalis). 1:

625 hordediene; 4: (+)-copalol; 5: miltiradiene; 6: abietatriene; 7: unknown copalol derivative. B. 626 
bioRxiv preprint doi: https://doi.org/10.1101/2021.05.21.445084; this version posted May 22, 2021. The copyright holder for this preprint (which

was not certified by peer review) is the author/funder, who has granted bioRxiv a license to display the preprint in perpetuity. It is made available under aCC-BY-NC-ND 4.0 International license.

Barley diterpenoid gene cluster
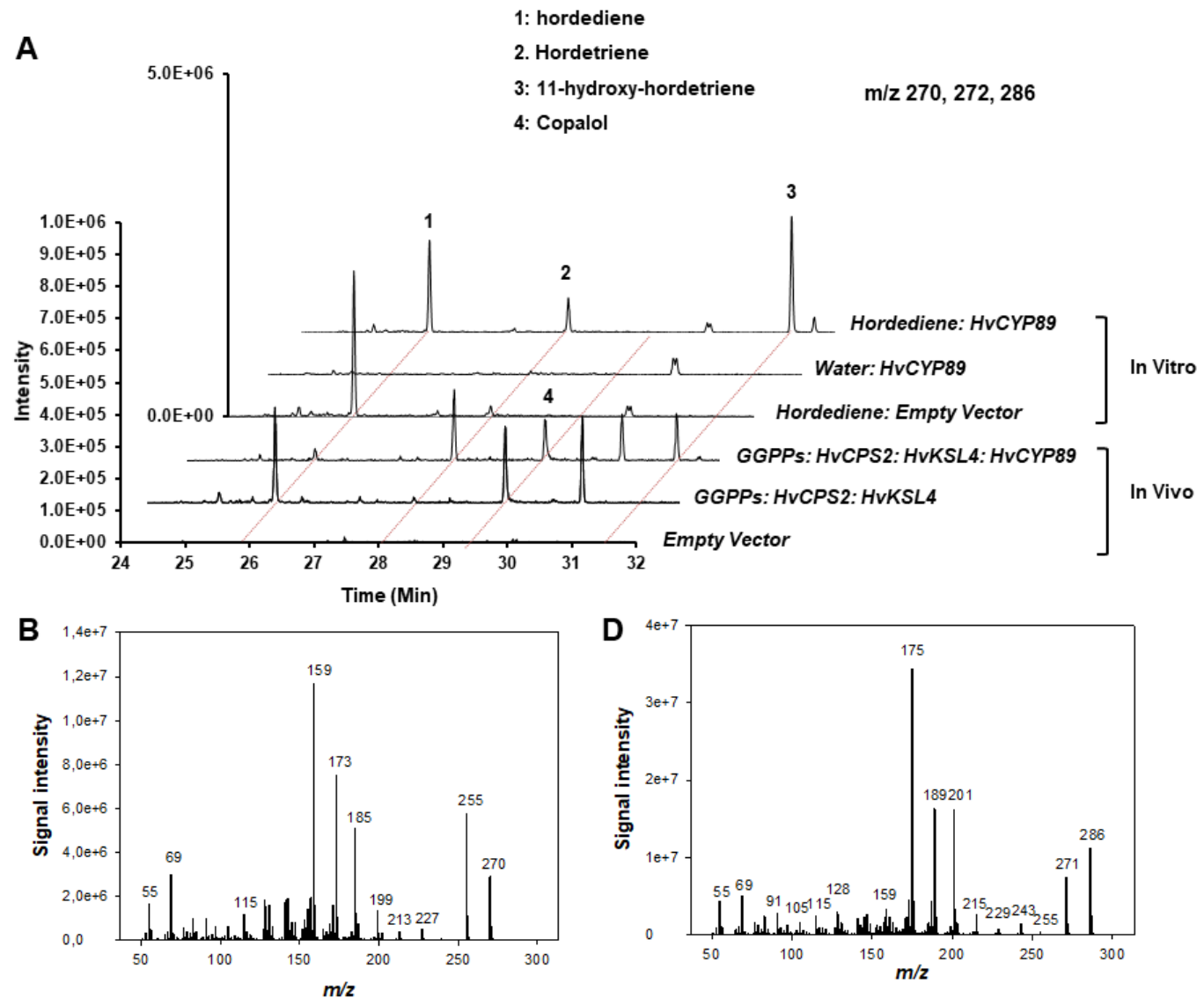

C

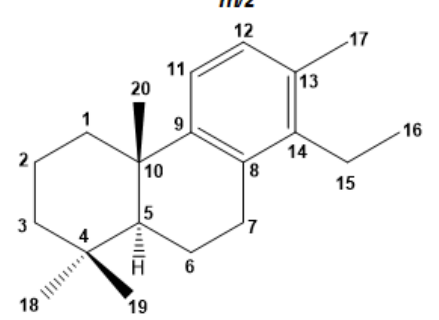

E

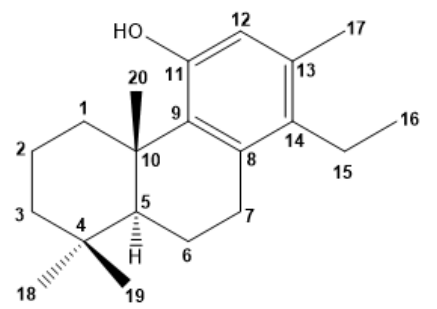

628 Figure 4. Characterization of HvCYP89E31. A. GC-MS chromatograms (single ion 629 monitoring for $\mathrm{m} / \mathrm{z} 270,272$ and 286). The in vivo chromatograms show analysis of extracts 630 from transient assays in $N$. benthamiana. The in vitro chromatograms show analysis of in 631 vitro assays with microsome fractions from yeast expressing HvCYP89E31. The identity of peaks is indicated by numbers. B and C. Respectively El mass spectrum and structure of compound 2, hordetriene. D and E. Respectively El mass spectrum and structure of compound 3, 11-hydroxy-hordetriene. 
bioRxiv preprint doi: https://doi.org/10.1101/2021.05.21.445084; this version posted May 22, 2021. The copyright holder for this preprint (which

was not certified by peer review) is the author/funder, who has granted bioRxiv a license to display the preprint in perpetuity. It is made available under aCC-BY-NC-ND 4.0 International license.

Barley diterpenoid gene cluster

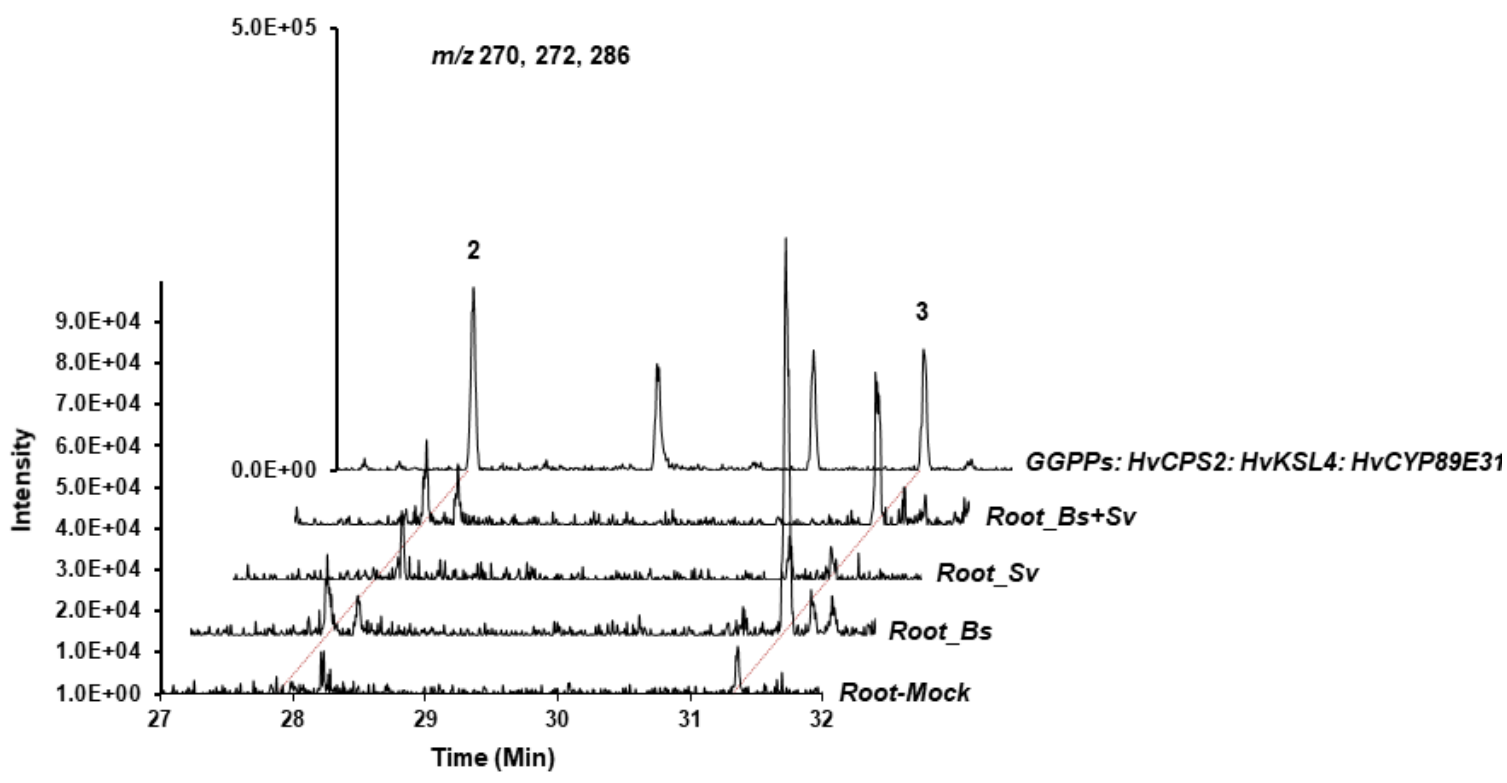

638 Figure 5. GC-MS chromatograms of extracts from barley roots infected with $B$. 639 sorokiniana and/or S. vermifera. Single ion monitoring ( $\mathrm{m} / \mathrm{z} 270,272$ and 286) of extracts 640 from roots infected with $B$. sorokiniana (Root_Bs), S. vermifera (Root_Sv) or both 641 (Root_Bs+Sv) or mock inoculated (Root-Mock). An extract of yeast strain expressing 642 HvCPS2, HvKSL4 and HvCYP89E31 is shown as a reference. 2: hordetriene; 3: 11-hydroxy643 hordetriene. 

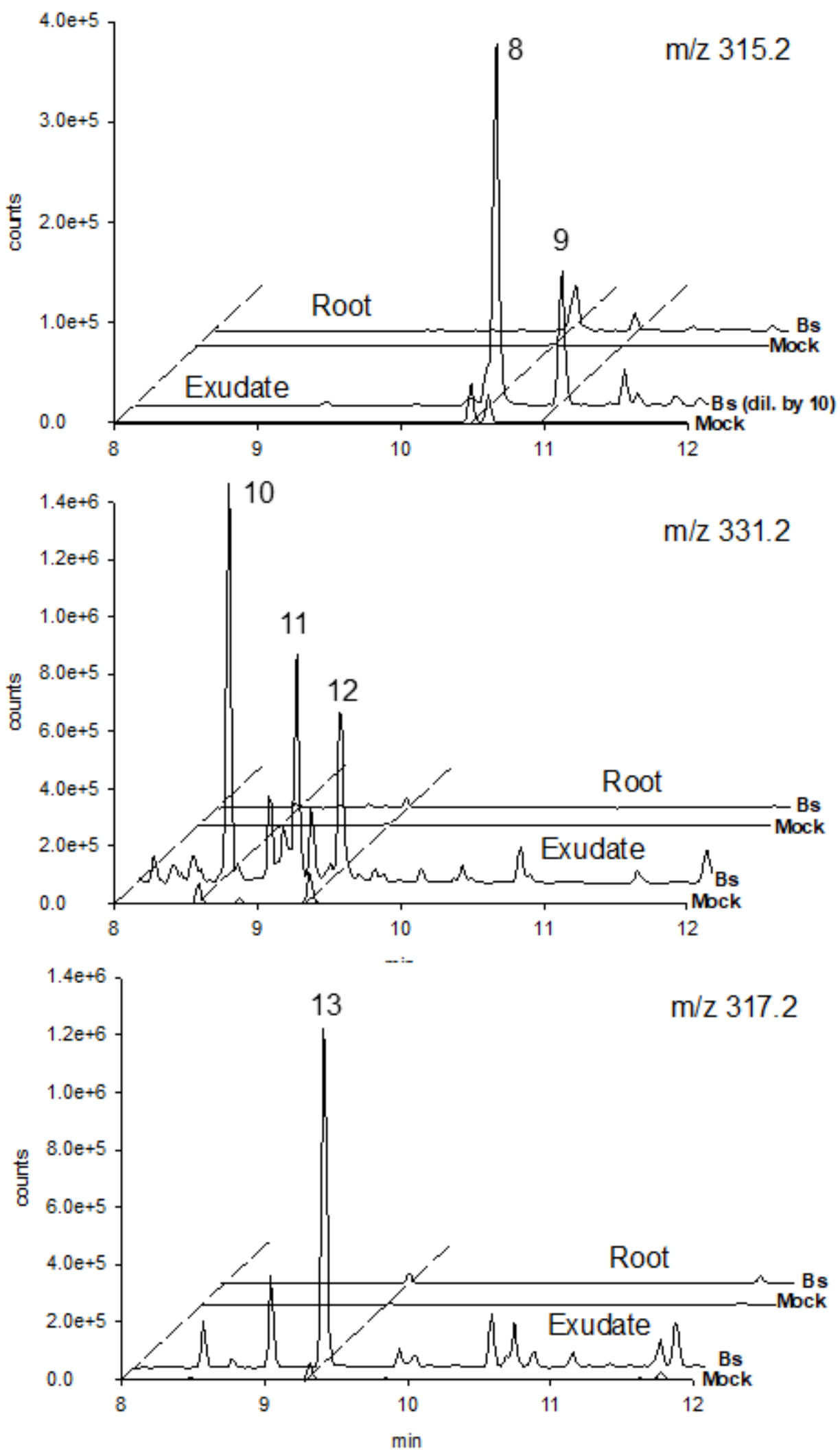

$\min$

645 Figure 6. LC-(-)ESI-QToF-MS of major diterpene metabolites in roots and root exudates 646 of barley 6 dpi with B. sorokiniana (Bs) and in respective mock infected controls. HR647 MS/MS spectra of compounds 8-13 are presented in Fig. S3. 
bioRxiv preprint doi: https://doi.org/10.1101/2021.05.21.445084; this version posted May 22, 2021. The copyright holder for this preprint (which

was not certified by peer review) is the author/funder, who has granted bioRxiv a license to display the preprint in perpetuity. It is made available under aCC-BY-NC-ND 4.0 International license.

Barley diterpenoid gene cluster

648

649

650

651

652

653

654

655

656

657

658

659

660

661

662

663

664

665

666

667

668

669

670

671

672

673

674

675

676

677

678

679

680

681

682

683

684

685

686

687

688

689

690

691

692

693

694

695

696

697

698

699

700

701

702

\section{References}

Ahuja, I., Kissen, R., and Bones, A.M. (2012). Phytoalexins in defense against pathogens. Trends in Plant Science 17, 73-90.

Akatsuka, T., Kodama, O., Kato, H., Kono, Y., and Takeuchi, S. (1983). Short Communication 3-Hydroxy-7-oxo-sandaracopimaradiene (Oryzalexin A), a New Phytoalexin Isolated from Rice Blast Leaves. Agricultural and Biological Chemistry 47, 445-447.

Awika, J.M. (2011). Major Cereal Grains Production and Use around the World. In Advances in Cereal Science: Implications to Food Processing and Health Promotion (American Chemical Society), pp. 1-13.

Ayer, W.A., and Khan, A.Q. (1996). Zythiostromic acids, diterpenoids from an antifungal Zythiostroma species associated with aspen. Phytochemistry 42, 1647-1652.

Badr, A., M, K., Sch, R., Rabey, H.E., Effgen, S., Ibrahim, H.H., Pozzi, C., Rohde, W., and Salamini, F. (2000). On the Origin and Domestication History of Barley (Hordeum vulgare). Molecular Biology and Evolution 17, 499-510.

Bathe, U., and Tissier, A. (2019). Cytochrome P450 enzymes: A driving force of plant diterpene diversity. Phytochemistry 161, 149-162.

Beier, S., Himmelbach, A., Colmsee, C., Zhang, X.-Q., Barrero, R.A., Zhang, Q., Li, L., Bayer, M., Bolser, D., Taudien, S., Groth, M., Felder, M., Hastie, A., Simková, H., Staňková, H., Vrána, J., Chan, S., Muñoz-Amatriaín, M., Ounit, R., Wanamaker, S., Schmutzer, T., Aliyeva-Schnorr, L., Grasso, S., Tanskanen, J., Sampath, D., Heavens, D., Cao, S., Chapman, B., Dai, F., Han, Y., Li, H., Li, X., Lin, C., McCooke, J.K., Tan, C., Wang, S., Yin, S., Zhou, G., Poland, J.A., Bellgard, M.I., Houben, A., Doležel, J., Ayling, S., Lonardi, S., Langridge, P., Muehlbauer, G.J., Kersey, P., Clark, M.D., Caccamo, M., Schulman, A.H., Platzer, M., Close, T.J., Hansson, M., Zhang, G., Braumann, I., Li, C., Waugh, R., Scholz, U., Stein, N., and Mascher, M. (2017). Construction of a map-based reference genome sequence for barley, Hordeum vulgare L. Scientific Data 4, 170044.

Bohlmann, J., Meyer-Gauen, G., and Croteau, R. (1998). Plant terpenoid synthases: Molecular biology and phylogenetic analysis. Proc. Natl. Acad. Sci. U. S. A. 95, 41264133.

Brückner, K., Božić, D., Manzano, D., Papaefthimiou, D., Pateraki, I., Scheler, U., Ferrer, A., de Vos, R.C., Kanellis, A.K., and Tissier, A. (2014). Characterization of two genes for the biosynthesis of abietane-type diterpenes in rosemary (Rosmarinus officinalis) glandular trichomes. Phytochemistry 101, 52-64.

Cartwright, D., Langcake, P., Pryce, R.J., Leworthy, D.P., and Ride, J.P. (1977). Chemical activation of host defence mechanisms as a basis for crop protection. Nature 267, 511-513.

Cheng, L., Ji, K.-I., Liao, S.-g., Gan, L.-s., Yang, L., Cao, D.-h., Liu, Y.-q., Guo, J., Zhang, P., Lu, C.-I., Hu, H.-b., and Xu, Y.-k. (2016). Diterpenoids and phenanthrenones from the leaves and stems of Strophioblachia fimbricalyx. Tetrahedron Letters 57, 2262-2265.

Deshmukh, S., Hueckelhoven, R., Schaefer, P., Imani, J., Sharma, M., Weiss, M., Waller, F., and Kogel, K.H. (2006). The root endophytic fungus Piriformospora indica requires host cell death for proliferation during mutualistic symbiosis with barley. $\mathrm{P}$ Natl Acad Sci USA 103, 18450-18457.

Ding, Y., Weckwerth, P.R., Poretsky, E., Murphy, K.M., Sims, J., Saldivar, E., Christensen, S.A., Char, S.N., Yang, B., Tong, A.-d., Shen, Z., Kremling, K.A., Buckler, E.S., Kono, T., Nelson, D.R., Bohlmann, J., Bakker, M.G., Vaughan, M.M., Khalil, A.S., Betsiashvili, M., Dressano, K., Köllner, T.G., Briggs, S.P., Zerbe, P., Schmelz, E.A., and Huffaker, A. (2020). Genetic elucidation of interconnected antibiotic pathways mediating maize innate immunity. Nature Plants $\mathbf{6}$, 1375-1388.

Hedden, P., and Kamiya, Y. (1997). GIBBERELLIN BIOSYNTHESIS: Enzymes, Genes and Their Regulation. Annu Rev Plant Physiol Plant Mol Biol 48, 431-460. 
bioRxiv preprint doi: https://doi.org/10.1101/2021.05.21.445084; this version posted May 22, 2021. The copyright holder for this preprint (which was not certified by peer review) is the author/funder, who has granted bioRxiv a license to display the preprint in perpetuity. It is made available under aCC-BY-NC-ND 4.0 International license.

Barley diterpenoid gene cluster

703

704

705

706

707

708

709

710

711

712

713

714

715

716

717

718

719

720

721

722

723

724

725

726

727

728

729

730

731

732

733

734

735

736

737

738

739

740

741

742

743

744

745

746

747

748

749

750

751

752

753

754

755

756

Hensel, G. (2020). Genetic transformation of Triticeae cereals - Summary of almost threedecade's development. Biotechnology Advances 40, 107484.

Huang, A.C.C., Jiang, T., Liu, Y.X., Bai, Y.C., Reed, J., Qu, B.Y., Goossens, A., Nutzmann, H.W., Bai, Y., and Osbourn, A. (2019). A specialized metabolic network selectively modulates Arabidopsis root microbiota. Science 364, 546-+.

Huffaker, A., Kaplan, F., Vaughan, M.M., Dafoe, N.J., Ni, X., Rocca, J.R., Alborn, H.T., Teal, P.E.A., and Schmelz, E.A. (2011). Novel Acidic Sesquiterpenoids Constitute a Dominant Class of Pathogen-Induced Phytoalexins in Maize Plant Physiology 156, 2082-2097.

Inoue, Y., Sakai, M., Yao, Q., Tanimoto, Y., Toshima, H., and Hasegawa, M. (2013). Identification of a Novel Casbane-Type Diterpene Phytoalexin, ent-10-Oxodepressin, from Rice Leaves. Bioscience, Biotechnology, and Biochemistry 77, 760-765.

Ishihara, A., Kumeda, R., Hayashi, N., Yagi, Y., Sakaguchi, N., Kokubo, Y., Ube, N., Tebayashi, S.-i., and Ueno, K. (2017). Induced accumulation of tyramine, serotonin, and related amines in response to Bipolaris sorokiniana infection in barley. Bioscience, Biotechnology, and Biochemistry 81, 1090-1098.

Karre, S., Kumar, A., Dhokane, D., and Kushalappa, A.C. (2017). Metabolo-transcriptome profiling of barley reveals induction of chitin elicitor receptor kinase gene (HvCERK1) conferring resistance against Fusarium graminearum. Plant Mol.Biol. 93, 247-267.

Kato, H., Kodama, O., and Akatsuka, T. (1993). Oryzalexin E, A diterpene phytoalexin from UV-irradiated rice leaves. Phytochemistry 33, 79-81.

Kato, H., Kodama, O., and Akatsuka, T. (1994). Oryzalexin F, a diterpene phytoalexin from UV-irradiated rice leaves. Phytochemistry 36, 299-301.

Kato, T., Kabuto, C., Sasaki, N., Tsunagawa, M., Aizawa, H., Fujita, K., Kato, Y., Kitahara, Y., and Takahashi, N. (1973). Momilactones, growth inhibitors from rice, oryza sativa L. Tetrahedron Letters 14, 3861-3864.

Kaufman, T.S., Mischne, M.P., Gonzalez-Sierra, M., and Ruveda, E.A. (1987). Synthesis and $13 \mathrm{C}$ nuclear magnetic resonance spectral analysis of some diterpenoids related to the cleistanthane type hydrocarbon isolated from Amphibolisantarctica. Canadian Journal of Chemistry 65, 2024-2026.

Kitaoka, N., Wu, Y., Zi, J., and Peters, R.J. (2016). Investigating inducible short-chain alcohol dehydrogenases/reductases clarifies rice oryzalexin biosynthesis. Plant $\mathbf{J} \mathbf{8 8}$, 271-279.

Kono, Y., Takeuchi, S., Kodama, O., and Akatsuka, T. (1984). Absolute Configuration of Oryzalexin A and Structures of Its Related Phytoalexins Isolated from Rice Blast Leaves Infected with Pyricularia oryzae. Agricultural and Biological Chemistry 48, 253-255.

Kono, Y., Uzawa, J., Kobayashi, K., Suzuki, Y., Uramoto, M., Sakurai, A., Watanabe, M., Teraoka, T., Hosokawa, D., Watanabe, M., and Kondo, H. (1991). Structures of Oryzalides A and B, and Oryzalic Acid A, a Group of Novel Antimicrobial Diterpenes, Isolated from Healthy Leaves of a Bacterial Leaf Blight-resistant Cultivar of Rice Plant. Agricultural and Biological Chemistry 55, 803-811.

Kumar, S., Stecher, G., Li, M., Knyaz, C., and Tamura, K. (2018). MEGA X: Molecular Evolutionary Genetics Analysis across Computing Platforms. Mol Biol Evol 35, 15471549.

Li, L., Chen, X., Ma, C., Wu, H., and Qi, S. (2016). Piriformospora indica requires kaurene synthase activity for successful plant colonization. Plant Physiology and Biochemistry 102, 151-160.

Liang, J., Shen, Q., Wang, L., Liu, J., Fu, J., Le, Z., Xu, M., Peters, R.J., and Wang, Q. (2021). Rice contains a biosynthetic gene cluster associated with production of the casbane-type diterpenoid phytoalexin ent-10-oxodepressin. New Phytol.

Livak, K.J., and Schmittgen, T.D. (2001). Analysis of relative gene expression data using real-time quantitative PCR and the 2(T)(-Delta Delta C) method. Methods 25, 402408. 
bioRxiv preprint doi: https://doi.org/10.1101/2021.05.21.445084; this version posted May 22, 2021. The copyright holder for this preprint (which was not certified by peer review) is the author/funder, who has granted bioRxiv a license to display the preprint in perpetuity. It is made available under aCC-BY-NC-ND 4.0 International license.

Barley diterpenoid gene cluster

Long, R.M., Lagisetti, C., Coates, R.M., and Croteau, R.B. (2008). Specificity of the Nbenzoyl transferase responsible for the last step of Taxol biosynthesis. Arch Biochem Biophys 477, 384-389.

Mascher, M., Gundlach, H., Himmelbach, A., Beier, S., Twardziok, S.O., Wicker, T., Radchuk, V., Dockter, C., Hedley, P.E., Russell, J., Bayer, M., Ramsay, L., Liu, H., Haberer, G., Zhang, X.-Q., Zhang, Q., Barrero, R.A., Li, L., Taudien, S., Groth, M., Felder, M., Hastie, A., Šimková, H., Staňková, H., Vrána, J., Chan, S., MuñozAmatriaín, M., Ounit, R., Wanamaker, S., Bolser, D., Colmsee, C., Schmutzer, T., Aliyeva-Schnorr, L., Grasso, S., Tanskanen, J., Chailyan, A., Sampath, D., Heavens, D., Clissold, L., Cao, S., Chapman, B., Dai, F., Han, Y., Li, H., Li, X., Lin, C., McCooke, J.K., Tan, C., Wang, P., Wang, S., Yin, S., Zhou, G., Poland, J.A., Bellgard, M.I., Borisjuk, L., Houben, A., Doležel, J., Ayling, S., Lonardi, S., Kersey, P., Langridge, P., Muehlbauer, G.J., Clark, M.D., Caccamo, M., Schulman, A.H., Mayer, K.F.X., Platzer, M., Close, T.J., Scholz, U., Hansson, M., Zhang, G., Braumann, I., Spannagl, M., Li, C., Waugh, R., and Stein, N. (2017). A chromosome conformation capture ordered sequence of the barley genome. Nature 544, 427-433.

Massalha, H., Korenblum, E., Tholl, D., and Aharoni, A. (2017). Small molecules belowground: the role of specialized metabolites in the rhizosphere. The Plant Journal 90, 788-807.

Miedaner, T., and Juroszek, P. (2021). Climate change will influence disease resistance breeding in wheat in Northwestern Europe. Theor. Appl. Genet.

Monat, C., Padmarasu, S., Lux, T., Wicker, T., Gundlach, H., Himmelbach, A., Ens, J., Li, C., Muehlbauer, G.J., Schulman, A.H., Waugh, R., Braumann, I., Pozniak, C., Scholz, U., Mayer, K.F.X., Spannagl, M., Stein, N., and Mascher, M. (2019). TRITEX: chromosome-scale sequence assembly of Triticeae genomes with opensource tools. Genome Biology 20, 284.

Muchlinski, A., Jia, M., Tiedge, K., Fell, J.S., Pelot, K.A., Chew, L., Davisson, D., Chen, Y., Siegel, J., Lovell, J.T., and Zerbe, P. (2021). Furanoditerpenoid biosynthesis in the bioenergy crop switchgrass is catalyzed by an alternate metabolic pathway. bioRxiv, 2021.2003.2030.437764.

Murphy, K.M., and Zerbe, P. (2020). Specialized diterpenoid metabolism in monocot crops: Biosynthesis and chemical diversity. Phytochemistry 172, 112289.

Murphy, K.M., Edwards, J., Louie, K.B., Bowen, B.P., Sundaresan, V., Northen, T.R., and Zerbe, P. (2021). Bioactive diterpenoids impact the composition of the rootassociated microbiome in maize (Zea mays). Sci Rep 11, 333.

Nakano, C., Okamura, T., Sato, T., Dairi, T., and Hoshino, T. (2005). Mycobacterium tuberculosis H37Rv3377c encodes the diterpene cyclase for producing the halimane skeleton. Chemical Communications, 1016-1018.

Nützmann, H.W., Huang, A., and Osbourn, A. (2016). Plant metabolic clusters - from genetics to genomics. New Phytol 211, 771-789.

Otomo, K., Kanno, Y., Motegi, A., Kenmoku, H., Yamane, H., Mitsuhashi, W., Oikawa, H., Toshima, H., Itoh, H., Matsuoka, M., Sassa, T., and Toyomasu, T. (2004). Diterpene cyclases responsible for the biosynthesis of phytoalexins, momilactones $A$, $B$, and oryzalexins A-F in rice. Biosci Biotechnol Biochem 68, 2001-2006.

Pelot, K.A., Chen, R., Hagelthorn, D.M., Young, C.A., Addison, J.B., Muchlinski, A., Tholl, D., and Zerbe, P. (2018). Functional Diversity of Diterpene Synthases in the Biofuel Crop Switchgrass. Plant Physiol 178, 54-71.

Pelot, K.A., Mitchell, R., Kwon, M., Hagelthorn, L.M., Wardman, J.F., Chiang, A., Bohlmann, J., Ro, D.K., and Zerbe, P. (2017). Biosynthesis of the psychotropic plant diterpene salvinorin A: Discovery and characterization of the Salvia divinorum clerodienyl diphosphate synthase. Plant J 89, 885-897.

Peters, R.J. (2010). Two rings in them all: The labdane-related diterpenoids. Natural Product Reports 27, 1521-1530.

Pichersky, E., and Lewinsohn, E. (2011). Convergent Evolution in Plant Specialized Metabolism. Annual Review of Plant Biology 62, 549-566. 
bioRxiv preprint doi: https://doi.org/10.1101/2021.05.21.445084; this version posted May 22, 2021. The copyright holder for this preprint (which was not certified by peer review) is the author/funder, who has granted bioRxiv a license to display the preprint in perpetuity. It is made available under aCC-BY-NC-ND 4.0 International license.

Barley diterpenoid gene cluster

813

814

815

816

817

818

819

820

821

822

823

824

825

826

827

828

829

830

831

832

833

834

835

836

837

838

839

840

841

842

843

844

845

846

847

848

849

850

851

852

853

854

855

856

857

858

859

860

861

862

863

864

865

866

867

868

Pichersky, E., Noel, J.P., and Dudareva, N. (2006). Biosynthesis of Plant Volatiles: Nature's Diversity and Ingenuity. Science 311, 808-811.

Riehl, C.A.S., and Pinto, A.C. (2000). A cleistanthane diterpene lactone from Vellozia compacta. Phytochemistry 53, 917-919.

Riehl, S. (2019). Barley in Archaeology and Early History (Oxford University Press).

Rontein, D., Onillon, S., Herbette, G., Lesot, A., Werck-Reichhart, D., Sallaud, C., and Tissier, A. (2008). CYP725A4 from yew catalyzes complex structural rearrangement of taxa-4(5),11(12)-diene into the cyclic ether 5(12)-oxa-3(11)-cyclotaxane. J Biol Chem 283, 6067-6075.

Rosyara, U.R., Subedi, S., Duveiller, E., and Sharma, R.C. (2010). The effect of spot blotch and heat stress on variation of canopy temperature depression, chlorophyll fluorescence and chlorophyll content of hexaploid wheat genotypes. Euphytica 174, 377-390.

Sallaud, C., Giacalone, C., Töpfer, R., Goepfert, S., Bakaher, N., Rösti, S., and Tissier, A. (2012). Characterization of two genes for the biosynthesis of the labdane diterpene Z-abienol in tobacco (Nicotiana tabacum) glandular trichomes. Plant J 72, 1-17.

Sarkar, D., Rovenich, H., Jeena, G., Nizam, S., Tissier, A., Balcke, G.U., Mahdi, L.K., Bonkowski, M., Langen, G., and Zuccaro, A. (2019). The inconspicuous gatekeeper: endophytic Serendipita vermifera acts as extended plant protection barrier in the rhizosphere. New Phytol 224, 886-901.

Scheler, U., Brandt, W., Porzel, A., Rothe, K., Manzano, D., Božić, D., Papaefthimiou, D., Balcke, G.U., Henning, A., Lohse, S., Marillonnet, S., Kanellis, A.K., Ferrer, A., and Tissier, A. (2016). Elucidation of the biosynthesis of carnosic acid and its reconstitution in yeast. Nat Commun 7, 12942.

Schmelz, E.A., Kaplan, F., Huffaker, A., Dafoe, N.J., Vaughan, M.M., Ni, X., Rocca, J.R., Alborn, H.T., and Teal, P.E. (2011). Identity, regulation, and activity of inducible diterpenoid phytoalexins in maize. Proceedings of the National Academy of Sciences 108, 5455-5460.

Sekido, H., Endo, T., Suga, R., Kodama, O., Akatsuka, T., Kono, Y., and Takeuchi, S. (1986). Oryzalexin D (3, 7-Dihydroxy-(+)-sandaracopimaradiene), a New Phytoalexin Isolated from Blast-infected Rice Leaves. Journal of Pesticide Science 11, 369-372.

Shimura, K., Okada, A., Okada, K., Jikumaru, Y., Ko, K.-W., Toyomasu, T., Sassa, T., Hasegawa, M., Kodama, O., Shibuya, N., Koga, J., Nojiri, H., and Yamane, H. (2007). Identification of a Biosynthetic Gene Cluster in Rice for Momilactones. Journal of Biological Chemistry 282, 34013-34018.

Shiono, Y., Ogata, K., Koseki, T., Murayama, T., and Funakoshi, T. (2010). A Cleistanthane Diterpene From a Marine-derived Fusarium Species Under Submerged Fermentation. Zeitschrift für Naturforschung B 65, 753-756.

Spielmeyer, W., Ellis, M., Robertson, M., Ali, S., Lenton, J.R., and Chandler, P.M. (2004). Isolation of gibberellin metabolic pathway genes from barley and comparative mapping in barley, wheat and rice. Theor Appl Genet 109, 847-855.

Tang, H., Bomhoff, M.D., Briones, E., Zhang, L., Schnable, J.C., and Lyons, E. (2015). SynFind: Compiling Syntenic Regions across Any Set of Genomes on Demand. Genome Biology and Evolution 7, 3286-3298.

Thiel, T., Graner, A., Waugh, R., Grosse, I., Close, T.J., and Stein, N. (2009). Evidence and evolutionary analysis of ancient whole-genome duplication in barley predating the divergence from rice. BMC Evolutionary Biology 9, 209.

Ube, N., Nishizaka, M., Ichiyanagi, T., Ueno, K., Taketa, S., and Ishihara, A. (2017). Evolutionary changes in defensive specialized metabolism in the genus Hordeum. Phytochemistry 141, 1-10.

Ube, N., Katsuyama, Y., Kariya, K., Tebayashi, S., Sue, M., Tohnooka, T., Ueno, K., Taketa, S., and Ishihara, A. (2021). Identification of methoxylchalcones produced in response to $\mathrm{CuCl} 2$ treatment and pathogen infection in barley. Phytochemistry 184, 10.

Urban, P., Mignotte, C., Kazmaier, M., Delorme, F., and Pompon, D. (1997). Cloning, yeast expression, and characterization of the coupling of two distantly related 
Arabidopsis thaliana NADPH-cytochrome P450 reductases with P450 CYP73A5. J Biol Chem 272, 19176-19186.

Wang, Q., Hillwig, M.L., and Peters, R.J. (2011). CYP99A3: functional identification of a diterpene oxidase from the momilactone biosynthetic gene cluster in rice. The Plant Journal 65, 87-95.

Watanabe, M., Sakai, Y., Teraoka, T., Abe, H., Kono, Y., Uzawa, J., Kobayashi, K., Suzuki, Y., and Sakurai, A. (1990). Novel C19-Kaurane Type of Diterpene (Oryzalide A), a New Antimicrobial Compound Isolated from Healthy Leaves of a Bacterial Leaf Blight-resistant Cultivar of Rice Plant. Agricultural and Biological Chemistry 54, 1103-1105.

Wawra, S., Fesel, P., Widmer, H., Timm, M., Seibel, J., Leson, L., Kesseler, L., Nostadt, R., Hilbert, M., Langen, G., and Zuccaro, A. (2016). The fungal-specific $\beta$-glucanbinding lectin FGB1 alters cell-wall composition and suppresses glucan-triggered immunity in plants. Nature Communications 7, 13188.

Weber, E., Gruetzner, R., Werner, S., Engler, C., and Marillonnet, S. (2011). Assembly of Designer TAL Effectors by Golden Gate Cloning. Plos One 6.

Wu, Y., Zhou, K., Toyomasu, T., Sugawara, C., Oku, M., Abe, S., Usui, M., Mitsuhashi, W., Chono, M., Chandler, P.M., and Peters, R.J. (2012). Functional characterization of wheat copalyl diphosphate synthases sheds light on the early evolution of labdanerelated diterpenoid metabolism in the cereals. Phytochemistry 84, 40-46.

Yadav, H., Dreher, D., Athmer, B., Porzel, A., Gavrin, A., Baldermann, S., Tissier, A., and Hause, B. (2019). Medicago TERPENE SYNTHASE 10 Is Involved in Defense Against an Oomycete Root Pathogen. Plant Physiol 180, 1598-1613.

Zheng, X.-H., Yang, J., Lv, J.-J., Zhu, H.-T., Wang, D., Xu, M., Yang, C.-R., and Zhang, Y.-J. (2018). Phyllaciduloids A-D: Four new cleistanthane diterpenoids from Phyllanthus acidus (L.) Skeels. Fitoterapia 125, 89-93.

Zhou, K., Xu, M., Tiernan, M., Xie, Q., Toyomasu, T., Sugawara, C., Oku, M., Usui, M., Mitsuhashi, W., Chono, M., Chandler, P.M., and Peters, R.J. (2012). Functional characterization of wheat ent-kaurene(-like) synthases indicates continuing evolution of labdane-related diterpenoid metabolism in the cereals. Phytochemistry 84, 47-55.

Zi, J.C., Matsuba, Y., Hong, Y.J., Jackson, A.J., Tantillo, D.J., Pichersky, E., and Peters, R.J. (2014). Biosynthesis of Lycosantalonol, a cis-Prenyl Derived Diterpenoid. J. Am. Chem. Soc. 136, 16951-16953. 